\title{
Sex and Gender Attributes in Rock Art in Six Counties in Utah
}

\author{
Samantha Shipley, BS in Anthropology ${ }^{1}$ a \\ ${ }^{1}$ Weber State University \\ Keywords: utah, archaeology, sex, gender, rock art \\ https://doi.org/10.36898/001c.17419
}

Curiosity: Interdisciplinary Journal of Research and Innovation

Vol. 2, 2021

\begin{abstract}
This study evaluates the ways gender and women's roles are interpreted in rock art in Utah. Six counties in Utah were evaluated - Box Elder, Carbon, Juab, Millard, Tooele, and Utah. Along with a review of relevant literature, the study drew on rock art site forms to review any indication of sex/gender attributes. Images and drawings proved to be the most beneficial in explaining how different symbols could indicate sex and gender attributes found among rock art. Though some rock art is easier to decipher, most is open to interpretation and requires extensive knowledge of the culture along with ethnographic analysis.

Understanding how gender is portrayed in rock art can give light as to how gender relations worked within a prehistoric society. This research can help in the "de-gendering" of archaeology and provide a different point of view to utilize when studying rock art. It may also aid in dismantling ethnocentric views within the field and contributing to non-archaeological sex and gender studies within different cultural contexts.
\end{abstract}

\section{Introduction}

In Utah, rock art emerged thousands of years ago by Native Americans groups that called this region home, and long before the arrival of Europeans and European-Americans. Rock art in Utah was created by Paleo-Indians, Anasazi, Fremont, Numic-speaking groups, and historically known tribes such as the Ute, Navajo (though much of it is up for debate due to the difficulties of dating rock art) (Schaafsma, 1971). Patterns and commonalities can identify each group's distinct style (Schaafsma, 1971, 1971). Common styles in Utah include the Barrier Canyon Style, Glen Canyon Style 5, Uncompahgre Style, San Juan Basketmaker Style, Pueblo I, and Pueblo II-III Style, Abajo-La Sal Style, and San Rafael Style (Schaafsma, 1971; Scotter \& Bowen, 2019). This paper will focus on Tooele, Utah, Juab, Carbon, Box Elder, and Millard counties, all located in the northern region of Utah.

\section{Rock Art's Place in Human History}

Sabo \& Sabo (2019) define rock art as "images rendered on immovable natural rock surfaces, such as bluff faces, cave walls, and large boulders”. It includes two common types (petroglyphs and pictographs). Petroglyphs are

\footnotetext{
a Samantha C. Shipley graduated from Weber State University in December 2019 receiving a Bachelor's of Science degree with a major in Anthropology and a minor in Geography. During the summer of 2019, she had the opportunity to intern with the Utah Division of State History under the direction of Dr. Christopher Merritt to study sex and gender attributions among rock art in Utah. In February 2020 she presented her research at the Utah Conference on Undergraduate Research. Currently, she is in the process of applying to graduate programs in hopes of studying biological anthropology. Samantha thoroughly enjoys all branches of anthropology, but has found biological anthropology to be the most compelling and something she would like to pursue as a career.
} 
created by removing parts of the rock surface, most commonly done by pecking or scratching away at the rock. Pictographs are created by painting on the rock surface with mineral and/or plant material (Cole, 2009). Though rock art can be ambiguous, it is still invaluable to understanding prehistoric humans. Rock art is more than scratches and paint splatters on rock; it is a way of socializing and offers a glimpse into prehistoric life utilizing patterns, distribution, and applied techniques. It also shows gender roles, ritual practices, record keeping, and a host of other uniquely human characteristics (Hays-Gilpin, 2004a).

With the help of rock art, we can better understand human behavior in past cultures all over the world. From an evolutionary standpoint, its emergence has helped us narrow down a time-frame when human intelligence began to skyrocket in comparison to other mammals (Bednarik, 2015). Rock art can provide evidence of when humans developed more complex social systems and the ability to understand the symbolic significance. It is the belief that people created the oldest known rock art somewhere between two to three hundred thousand years ago in India (Bednarik, 2015). Symbolic creation reflects the divergence of Homo sapiens from other mammal species. It shows a significant leap in humans' cognitive abilities and helps us to understand the evolution of our species.

Investigations into rock art in contemporary societies have shown us how previous people lived, how they obtained food, their social initiation practices, and much more (Bednarik, 2015; Brady, 2016; Sabo \& Sabo, 2019). Rock art also expresses group ideology and identity, migration patterns, landscape use, sacred/profane space, and other human universals that continue today (McMurtrey, 2015). The models we use to interpret rock art can also be useful in understanding contemporary ideologies and dynamics (e.g., Rogers, 2007, p. 87). The shamanic/neuropsychological model, originally developed by David Lewis-Williams, points to shamanism as the primary reason for the creation of rock art. David Whitley has applied this model to much of the rock art found in the Great Basin region (Whitley, 1998). The problem with this model is that it does not include women because women were not shamans in the studied cultures (Rogers, 2007, pp. 92-94).

While some rock art can be dated and explained through ethnography or material culture, rock art in most archaeological contexts remains enigmatic. For instance, ethnographic studies and stories from the artists' descendants identifies San rock art in Sub-Saharan Africa (Solomon, 1997). However, rock art found in West Norway at a site called Vingen has been particularly puzzling in identifying both the who and when of its creation. Rock art with no distinguishing time-frame features such as other artifacts or ethnographies can be more challenging to place on a timeline. Early attempts at dating the Vingen rock art site placed it somewhere between "the Early Neolithic until the end of the Middle Neolithic, with a possible origin in the Late Mesolithic" (Lødøen, 2003). This estimation was proposed based on the archaeological material and the relation to nearby shorelines. 
Ethnography is essential for archaeologists in interpreting their findings, including rock art. Liam A. Brady expresses the importance of ethnography "to develop a better understanding of how significance and value are attributed to sites and motifs" (Brady, 2016). We can interpret a petroglyph of an anthropomorphic figure with a line with a pointy tip at the end of what appears to be an arm in many ways. If we know the art is by the ancestors of a society that still obtains their food through hunter-gatherer practices like their ancestors, we can more confidently conclude the line with a pointy tip is a spear. In the example of San rock art, we can cross-reference their stories, myths, and present cultural practices to understand their past cultural practices and rock art. We use ethnographies to understand other aspects of past cultures as well. Many religious rituals, ceremonies, prayers, etc. are passed down to each generation and remain relatively unaltered.

With or without ethnographic connections, researchers must use scientific and archaeological methods to provide more formal dating methods. The chronology of rock art has been one of the most fundamental, though challenging, aspects of classification, and interpretation (Liritzis, 2010; Lødøen, 2003). These methods are either relative or absolute dating methods. Relative dating methods are largely based on observations, while absolute methods consist of running scientific tests with the material at the site. Distinguishing between a petroglyph and pictograph determines which method to use. Relative dating methods can be somewhat subjective due to the fact that they rely on a researcher's observations (this includes any biases they may have). James D. Keyser (2001) describes eight ways to relatively date rock art including association with dated archaeological deposits, association with dated portable (mobile) art, portrayal and datable subject matter (horses in the New World for instance), superimposition of designs, rock varnish and weathering, physical access to images, ethnographic knowledge, and materials used in the production of the art. For example, Trond Lødøen (2003) describes how the location of the art and geological factors, equivalent to the shoreline or an area, can give us an idea of when the art was created, but it isn't always accurate or sufficient enough to lead to more analysis. Many archaeologists categorize and associate different 'styles' of rock art with different groups based on ethnographic knowledge (Rosenfeld \& Smith, 2002). This leaves room for biases and false assumptions which takes scientific method out of the research.

Absolute dating methods, on the other hand, are much more precise and can provide us with a more definite time frame, rather than an estimation. Most absolute dating methods cannot be used on petroglyphs because there is little to no organic material to extract. However, in some instances, it is possible if mineral material has formed over the engraving (Geib \& Fairley, 1992). Radiocarbon dating is one of the first absolute dating methods applied to rock art. The first direct radiocarbon date of rock art was published in 1987 by Hedges et al. (Hedges et al., 1987) and has since been used to date many archaeological sites. One can use radiocarbon dating with pigment from a pictograph (Bednarik, 2015) and determine the age of the carbon component. 
Charcoal pigments are the most reliable matter when determining age, though it can only yield the maximum age of the pigment (Rowe, 2001). However, "The accuracy of the radiocarbon dating method decreases as the age of the sample increases" (Sauvet, 2015). Accuracy is dependent on pigment contamination (Bowen \& Manning, 2003). One example highlights a Fremont rock art site where testing was done on a charcoal pigment and an associated artifact (Geib \& Fairley, 1992). Another example of a site that was able to be dated is the Great Gallery panel in Canyonlands National Park. With a full alluvial stratigraphy and a rockfall event that were easily datable, the exposure time proved the rock art dated to the transition to agriculture in the Colorado Plateau (Pederson et al., 2014).

Thermoluminescence and optically stimulated luminescence dating have also proved to be a useful method in dating rock art. Thermoluminescence consists of heating matter to $275^{\circ} \mathrm{C}$ and subjecting it to known irradiation doses to calculate the paleodose. This form of dating has been done using calcite deposits. A similar method is Optically Stimulated Luminescence (OSL). This method uses light instead of heat to stimulate luminescence (Sauvet, 2015). Researchers are still testing both methods to obtain more accurate dates.

\section{Research Background}

\section{Defining Women/Gender Roles in Anthropology}

It is important to understand the difference between gender and sex before defining and understanding gender roles. Sex makes up biological differences determined by a person's chromosomes. There are two sexes: female and male. Society determines a person's gender, and the results of behaviors largely depend on one's sex. "As there is a natural normality that makes differences at a biological level, there is also a cultural normality, which is linked by what is naturally in a certain culture" (Neculaesei, 2015). Some societies recognize two genders- women and men- however, some cultures recognize many different categories. There are even cultures that consider all children the same gender until they reach puberty or go through an initiation ritual or rite of passage (Hays-Gilpin, 2004b). While sex is permanent (genetically), gender can change over time (Neculaesei, 2015). For example, a person may be born a female based on genetics and reproductive organs, but decide they identify as male later in life. Their sex remains the same, but their gender changes (including their roles in society based on their culture).

Lee Bader (2014) gives three examples of cultures that include a "third gender" in Third Genders: New Concept? Or Old? In Hawaii, before its colonization, there was a long-standing multiple gender tradition, where the mabu could be a male or female biologically but decide to inhabit a gender role either opposite theirs, somewhere in between the traditional sex roles, or even both masculine and feminine roles. In ancient Incan culture, the Incas worshipped a "dual gendered god" known as chuqui chinchay, who could only be attended and honored by third gender shamans or servants who wore androgynous clothing as "a visible sign of a third space that negotiated between 
the masculine and the feminine, the present and the past, the living and the dead." Finally, among the Sakalavas of Madagascar, there is a third gender group reserved especially for little boys thought to have a feminine appearance and personality.

Religious, philosophical, and political discourses transmit values and norms to us. They tell us what is expected and accepted for men and women, and what each gender prohibits. The most critical factor in gender transmission is communication. Communication enables people to learn how to be men and women (Neculaesei, 2015). Western cultures expect women to be the primary caretakers of children, while men are expected to work and support the family. This social construct is not a human universal but is common among patriarchal societies. Matriarchal societies usually have opposite roles as patriarchal societies. The Mosuo, found in China near the border of Tibet, are an example of a matriarchal society. Each household has a head matriarch, and the mother's side traces family lineage. Women in the Mosuo culture hold leadership roles, which is not the case in many Western societies (Garrison, 2017; WorldAtlas \& Sawe, 2019). Other forms of gender expression include the type of clothing one wears, the way they communicate, and the type of work they participate in. One's gender determines their role in society and stems from the society's cultural values/norms, religious aspects, and historical and environmental factors. Thus, gender roles can differ greatly between societies.

\section{Sex/Gender E' the Cosmos in Rock Art}

When studying prehistoric material, including rock art, it is important to keep in mind that we cannot impose current gender roles on past cultures. We must interpret prehistoric material on a case-by-case basis and not apply our own cultural values and norms to their society. Regardless, rock art can help us to understand a culture's gender roles because it socializes a landscape and is an expression of activities, values, and norms within a culture, but the difficulty is in its interpretations. Understanding the gendered dimension can be useful in comprehending sex/gender roles, migration patterns, ethnogenesis, and cultural affiliation. Whether it be an explicit representation of sex (genitalia) or an implicit one, distinct examples of sex/gender are present in rock art. The placement of the image can also be a way of expressing sex/gender. For example, features of a rock, such as a crevice, can be incorporated into the rock art to represent a vagina (Hays-Gilpin, 2004a).

There are some cases where rock art has played an active role in gendering members of a community. Initiation rituals from girl to woman are present in rock art images. Petroglyphs found in the Columbia Plateau have aided archaeologists in understanding puberty seclusion sites and rituals for both boys and girls (Bass, 1994; Hays-Gilpin, 2004a). There is also an example of women producing and utilizing rock art for puberty rites in southwestern California (Bass, 1994, p. 69; Rogers, 2007, p. 97). Rock art has also been known to preserve the rituals and dynamics of gender within a culture (Frink et al., 2002). 
Another example of gendered roles commonly found in rock art is hunting. The connection between symbols of masculinity and weapons is possibly a way of depicting competition and archiving hunting successes. Richard A. Rogers argues there is an abundance of (predominantly male) hunting activity depicted in rock art. This is due to a male dominance crisis that occurred as subsistence shifted from hunting, a male activity, to gathering, a female activity. The change potentially enabled women to become more independent and men more dependent on women and marriage, leading men to turn to shamanism and present their activities as significant via rock art. The problem with this explanation fails to acknowledge that cross-cultural evidence fails to support the "men are hunters/women are gatherers" stereotype. However, some differences among anthropomorphic figures may not be sex/gender, but instead different roles in society. Hays-Gilpin explains how these differences can represent something as simple as warriors vs. non-warriors (Hays-Gilpin, 2004a; Rogers, 2007, pp. 79-90).

While most anthropomorphic rock art lacks sex attributes, it is essential to note some sex distinctions. Symbols for male genitalia can include a line between the legs or a knob at the end or two dots for testes. Symbols for female genitalia include a dot/cupule, two short lines, three short lines, a triangle, or a combination between the legs (Hays-Gilpin, 2004a). A standard among rock art, especially art found in North America, is the apparent absence of women. Although, if we could better interpret the art, this may not be the case. One problem arising when trying to gender an anthropomorphic figure is gender fluidity, which is common among some Native American cultures (Hays-Gilpin, 2004a; Rogers, 2007, pp. 89-96).

On gendered symbols in rock art, Patricia Bass explains how de-gendering rock art does not mean no gender representation, but "if gender is important, then not all representations should be male" (Bass, 1994, p. 70). De-gendering is removing any assumptions or biases one may have regarding gender/gender roles when attempting to interpret rock art. By de-gendering the art, we don't impose our gender roles on past cultures. Bass further explains how the commonly used "shamanic" hypothesis can be problematic. If we employ this hypothesis, we need to be aware of gendered symbols within shamanic practices as well. Furthermore, there may be other sexual motifs we are ignoring if we assume the art originated from shamanic practices (Bass, 1994, p. 70).

A study by Catherine Namono (2005) on female issues found in a Northern Sotho site in South Africa highlights the importance of using ethnographic research to interpret rock art more effectively. Previous research on the art has only focused on boys' initiation rituals and colonial contract art depictions. Much of the art at the site included geometric figures and images resembling clothing primarily worn by women. After using ethnographies, they were able to link the art to women artists and assume any geometric art in the area is related to women as the images may implicitly or explicitly depict women's issues, such as menstruation and birth. Namono emphasized the importance of authorship in interpreting the rock art (Namono \& Eastwood, 2005, p. 77). 
Another necessary aspect to understanding rock art is the cosmos, which is instrumental in many religions and cultures. Cosmos means "ordered world" and represents a way to get closer to a god or "grand creator" by many religions (Mullen, 2011). Many religions believe in tiered cosmos that represent different levels of life and spirituality. The tiered cosmos have a lower, middle, and upper world. The lower world is usually associated with death, birth, ancestors, and danger, the middle world represents the earth's surface, and the upper world is typically the sky and celestial bodies. In order to travel between the worlds, there is a pathway known as the axis mundi that connects the worlds in the universe (Wright \& Russell, 2011).

Found cross-culturally across the North American Southwest, the pipette is an uncommon rock art motif representing a tiered cosmos. Many ethnographic explanations of the pipette give a common theme: religion, connection to another place, and transcendence. Wright and Russell argue the pipette is undoubtedly a religious symbol due to its prominence, visibility, association with shrines, and astronomical context (Wright \& Russell, 2011). The pipettes and rock art, in general, can be vital to comprehending a culture's cosmos (Namono, 2012) and how they view their place in the world.

Another common symbol that archeologists believe represents the cosmos are dumbbells and concentric circles found in Pygmy rock art in Uganda. Catherine Namono argues the dumbbells represent male genitalia, and the concentric circles represent female genitalia. The conclusion draws from a combination of cosmology and ethnographic analysis. This example is useful in understanding how ethnographies help to better explain prehistoric rock art (Namono, 2012).

\section{Women's Roles in Rock Art}

Whether it be in depiction or authorship, women's roles in rock art are still unclear and seldom researched. This could be due to the fact that broader, system-level processes were of more interest (Wylie, 2002). It could also be due to archaeology as a profession being predominantly male and thus focused on expressions of masculinity (especially with hunting). Most anthropomorphic rock art lacks sexual attributes. Male genitals have been depicted as a line between the legs with an occasional knob at the end and two dots for testes. Female genitals are sometimes portrayed as a dot/cupule, two short lines, three short lines, a triangle, or a combination of the symbols between the anthropomorphic figure's legs.

It is also difficult to determine if variation in anthropomorphic figures are representing gender or role (Hays-Gilpin, 2004b). For example, could two figures with different head shapes represent gender? Possibly, but they could also represent a shaman vs. a non-shaman, a warrior vs. a non-warrior, or a child vs. an adult. Without ethnographic incorporation, we cannot say for certain male and female differences have been depicted.

Another reason gendering rock art can be problematic is the androcentric belief that females' only function is reproduction. It is oppressive but commonly assumed that any rock art depicting women is going to revolve 
around reproduction, birth, and childcare (Handsman, 2002). It also relies on the belief that women's roles in society have remained unchanged since the rock art was created (Wylie, 2002). Unless ethnographic research provides defined roles for women in a society, we cannot assume that their roles were the same as modern women's.

\section{Methods}

\section{Literature Review and Data Collection}

For this research, I completed a review of existing literature to evaluate the ways in which gender is found or expressed in Utah rock art. A few key books were Engendering Archaeology by Margaret W. Conkey and Joan M. Gero (2002) and Ambiguous Images by Kelley Hays-Gilpin (2004a). The first book provides a way to better understand how gender fits into archaeology. The second book was useful to understand the ambiguity of rock art. Janet D. Spector's (1993) What this Awl Means served as a useful foundation in my research to understand how biases can impact archaeological research.

Data collection of site-specific information was completed with the help of the Archaeological Records Manager for the Antiquities Section within the Utah Division of State History. As the central repository for archaeological site information in Utah, the Antiquities section holds records for over 100,000 known archaeological sites, including rock art. The records manager executed a site query on the comprehensive archaeological database based on spatial location and site type. First, in conversations with the records manager, it was important to narrow the scope of the proposed project to a few counties in northwestern Utah. The query was thus narrowed to Box Elder, Carbon, Juab, Millard, Tooele, and Utah counties. From within those counties, the query was narrowed down by prehistoric features: petroglyphs and pictographs. The search resulted in 751 site forms that were reviewed for any indication of sex/ gender attributes. For the author's reference, archaeological sites in Utah use a Smithsonian Trinomial system meaning that the first two numbers are the state code for Utah (42), followed by a two-letter code for the county (BO for Box Elder for example) and then a sequential series of numbers for which site number this is for that county (so 2300 is the twenty-three hundred site documented in that county).

\section{Qualitative Methods}

Qualitative methods included analysis of sites, including sex/gender attributes. This method proved to be the most important way of determining the amount of sex/gender attributes found among rock art in Utah.

\section{Quantitative Methods}

Quantitative methods included counting the number of rock art sites displaying sex/gender attributes. Around only $3 \%$ of sites included possible sex/gender attributes. 


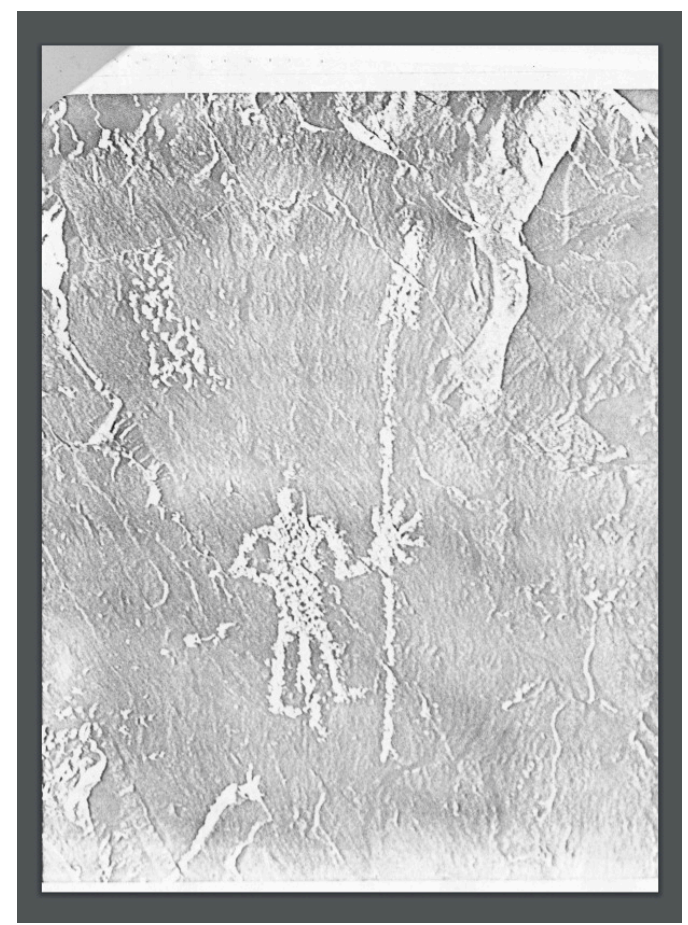

Figure 1: Anthropomorph with a line in between legs and a spear in hand.

Source: Barger, 1978

\section{Results}

\section{Rock Art Observation}

While reviewing the site forms, the following sites were noted based on any sex/gender attributes they contained. Attributes included genitalia (extra lines between the legs, two dots for testes, cupules, etc.) and concentric circles. Though there is likely more rock art with gender representation than listed below, these were the most obvious. The following are examples of possible gender representation in rock art in six Utah counties based on the type of sex/ gender attribute.

\section{Anthropomorphs with Lines Between their Legs}

Site 42BO386, shown below, includes an anthropomorphic figure with a line between the legs. The figure has one hand holding a spear and has extremities. The line between the legs is longer than the original legs and does not have a foot like the others. This could represent a number of things: a third leg, a tail, or a penis. However, if it were a tail, it would likely be off to the side as it is at site $42 \mathrm{BO} 1703$. If it were a third leg, it would probably be the same length as the other two legs. Though the third line could very well be a tail, third leg, or something unknown, it also stands to reason that it represents a penis (Barger, 1978; Stuart, 2007a).

Site 42BO2114 includes two anthropomorphic figures with a single, smaller line between the legs. The second figure (Figure 3) has a knob at the end of the line (Stuart, 1985). 


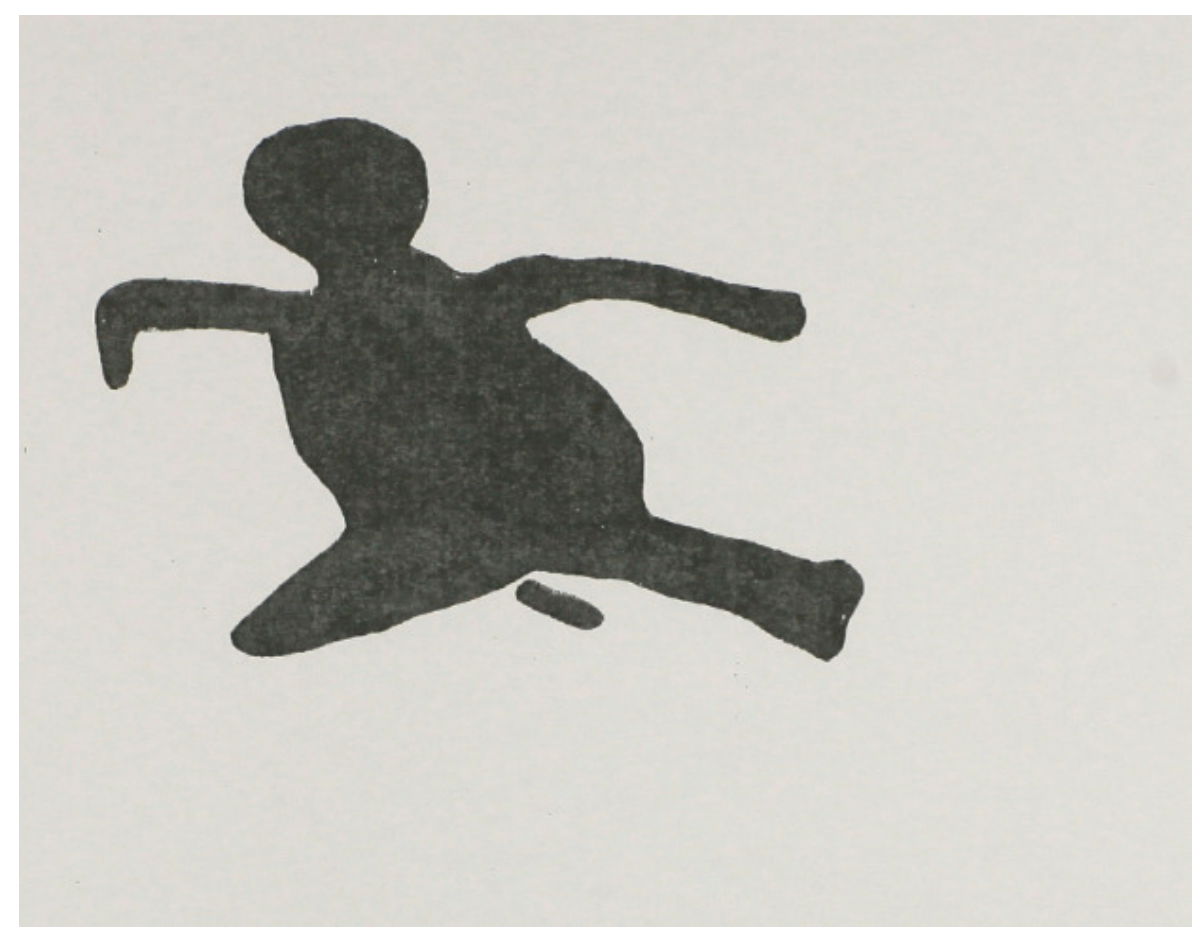

Figure 2: Anthropomorph with a line in between legs.

Source: Stuart, 1985

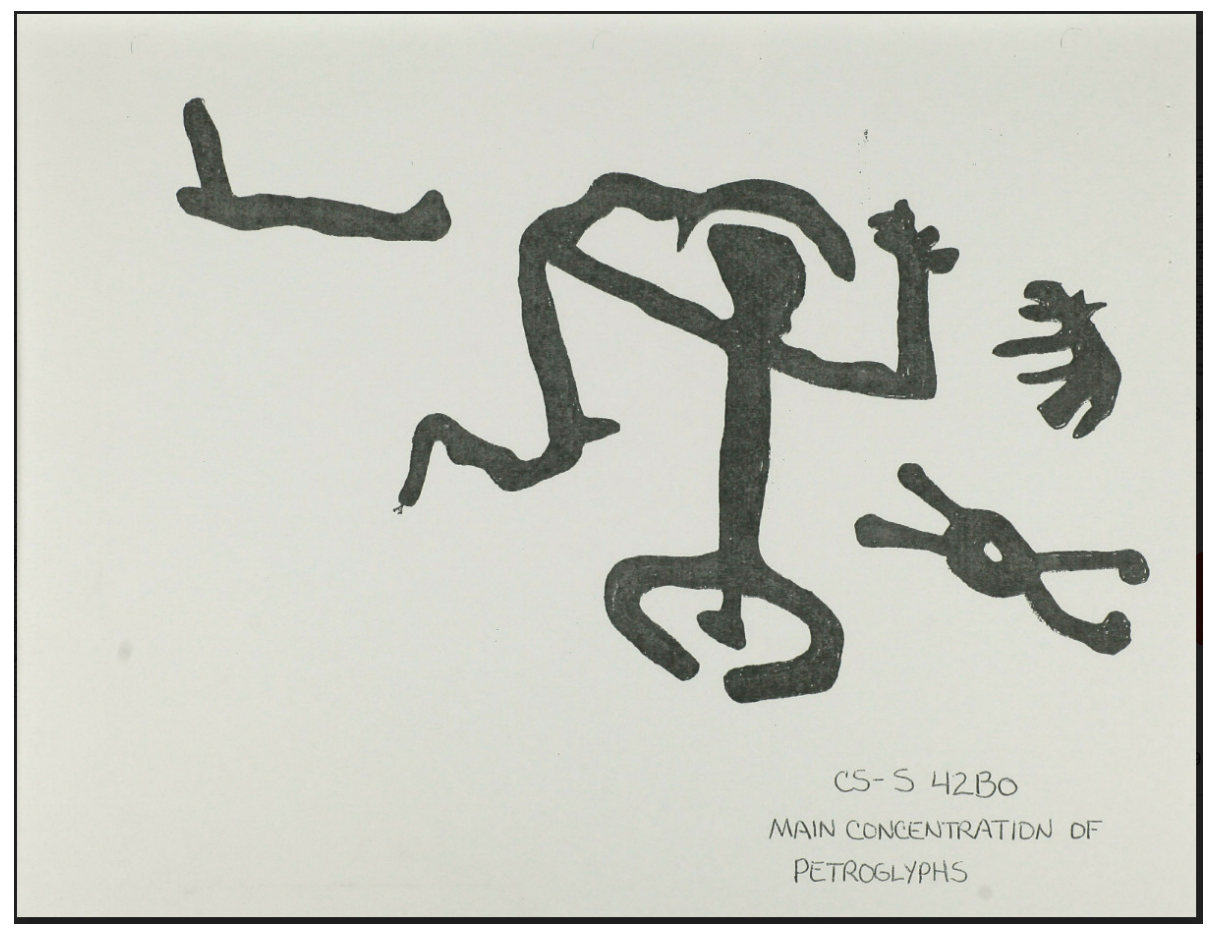

Figure 3: Anthropomorph with a line and knob in between legs.

Source: Stuart, 1985

Site 42CB958 shows another example of a figure with a line between the legs, extremities, and a ring-shaped head. The figure has an interesting body shape as well (Spangler, 2007).

Site $42 \mathrm{CB} 1045$ is another example of an anthropomorphic figure with a line in between the legs (Miller, 1996). 


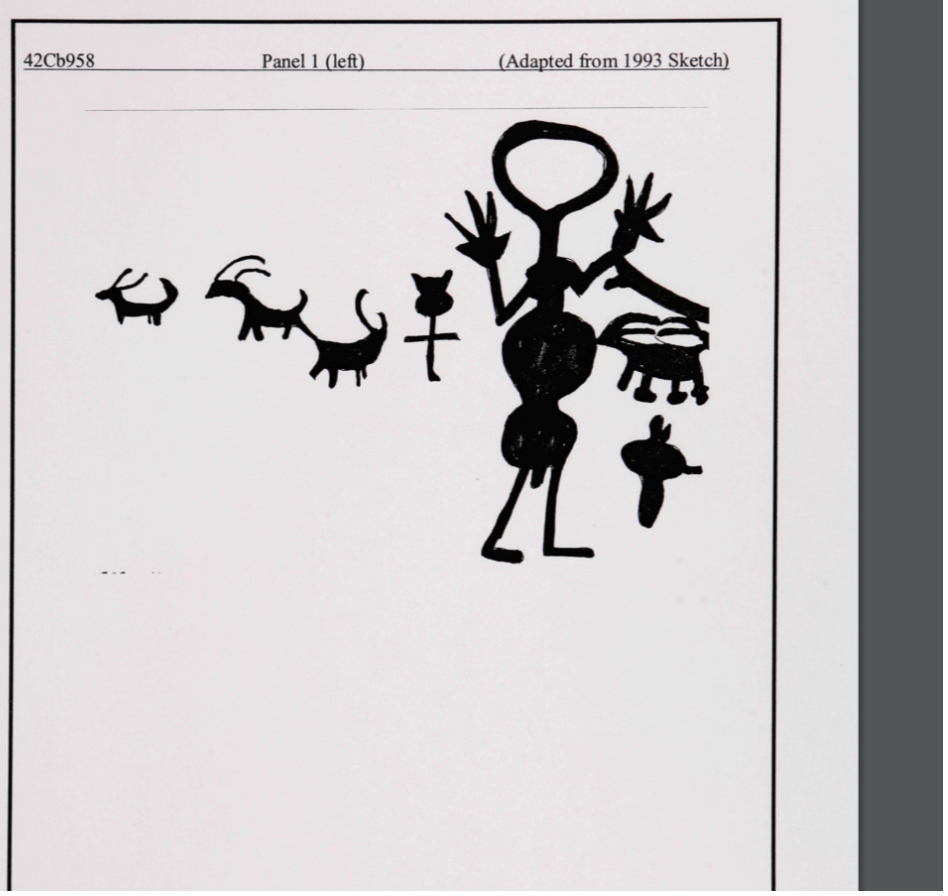

Figure 4: Anthropomorph with a small line in between legs.

Source: Spangler, 2007

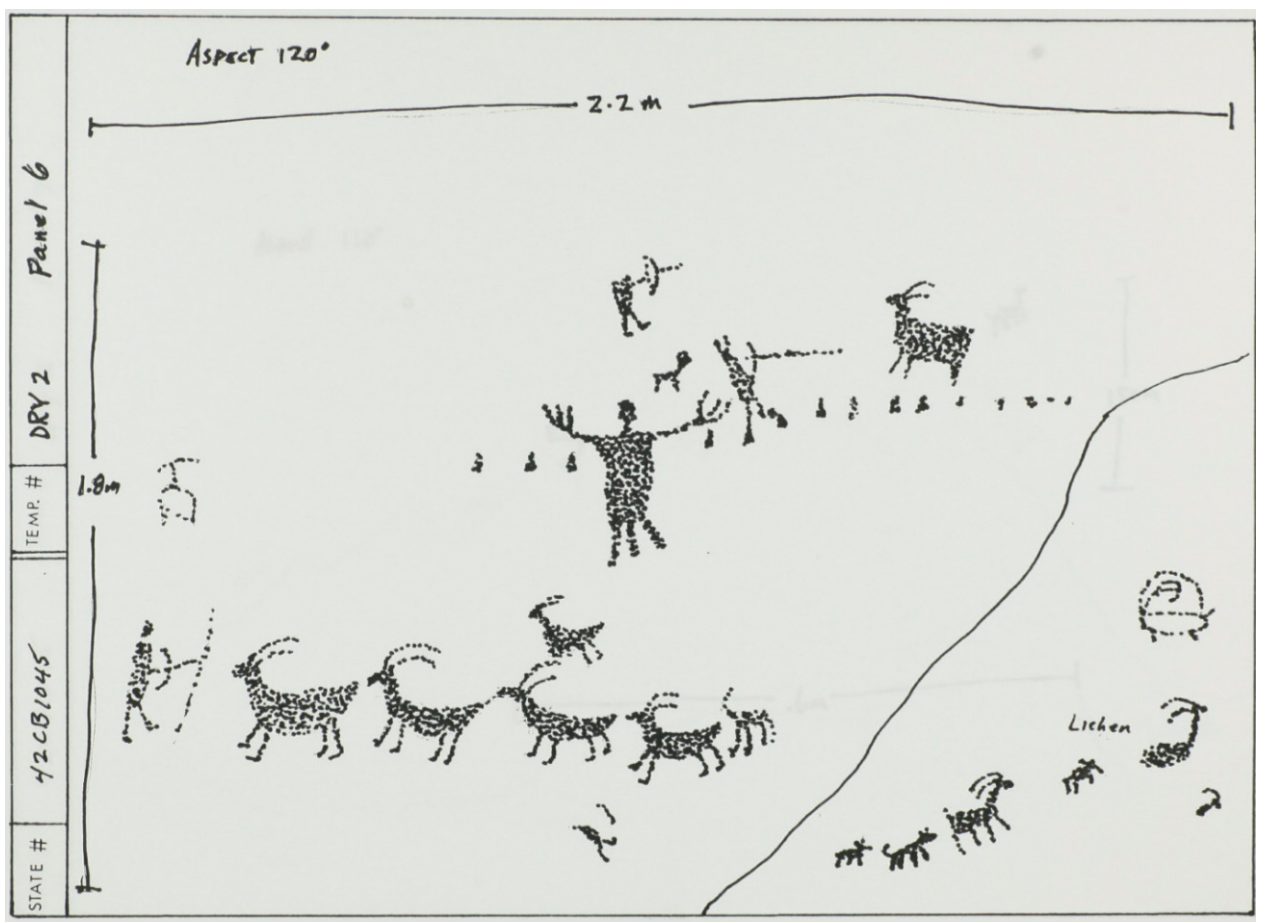

Figure 5: Anthropomorph with a line in between legs.

Source: Miller, 1996

Site 42UT1586 portrayed in the sketch below shows a petroglyph rock art panel in Utah County. There are three anthropomorphic figures depicted. All three figures have similar body and head shape; however, the figure on the left 


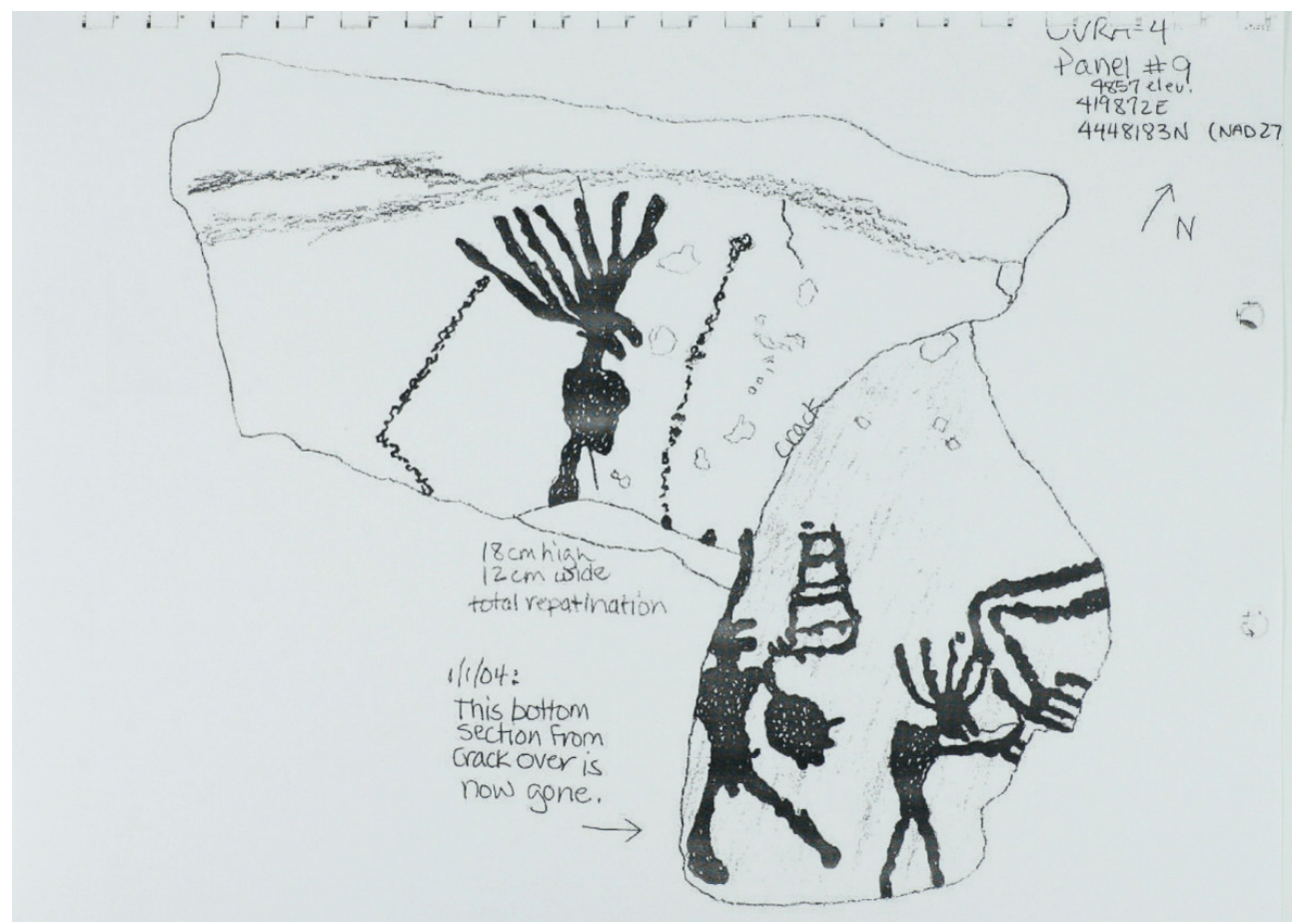

Figure 6: Three anthropomorphs, one with a line in between legs.

Source: Healy, 1999

appears to have only one leg and no arms. The figure in the middle has a small line in between their legs, which could be a symbol for a male (Hays-Gilpin, 2004a; Healy, 1999).

\section{Antbropomorphs of Varying Sizes and Shapes}

Site 42BO400 shows around ten different anthropomorphs in varying sizes and shapes. The varying body shapes and sizes could be meaningless, but could also represent different sexes because biologically, men are typically larger than women. Mark E. Stuart first documented this site in 1982. I've included his original drawings below for reference (Stuart, 1982).

Site BO412 is another example of anthropomorphs of different sizes, possibly representing sex differences or adults and children. The image shows what is likely an adult and a child due to the significant size differences (Stuart, 1982).

Site 42BO1705, nicknamed Big Man/Little Man Rock, includes a possible adult and child figure connected by a circular object. The recorder noted the circular shape could be a shield. Again, the size differences could be age or gender representations (Stuart, 2007a).

Site 42UT1784 includes anthropomorphs of different sizes, possibly representing various ages or genders. The smaller figure appears to have a line between the legs (Manning, 2011).

Site 42BO1707 has one panel with a group of three anthropomorphs of varying sizes (Stuart, 2007b). 


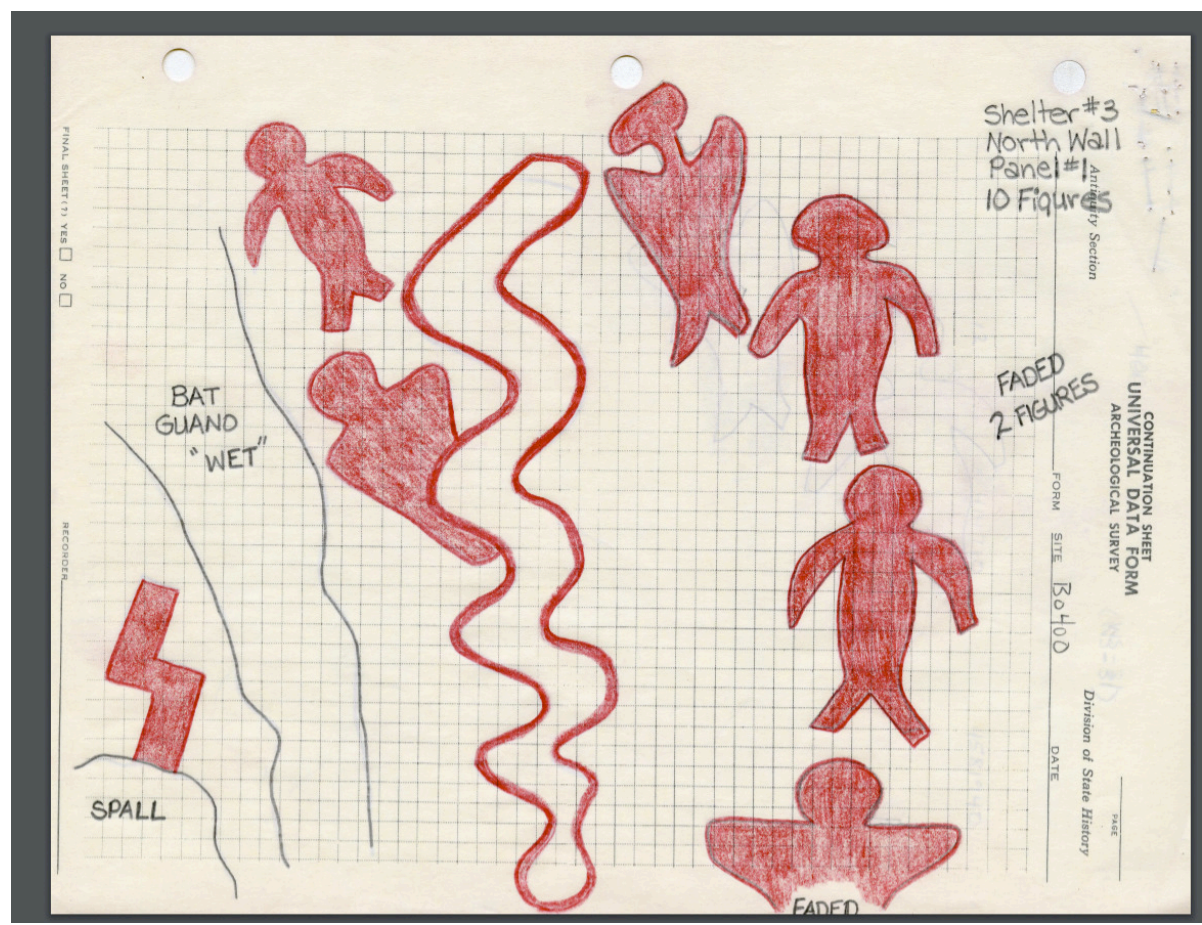

Figures 7

Source: Stuart, 1982

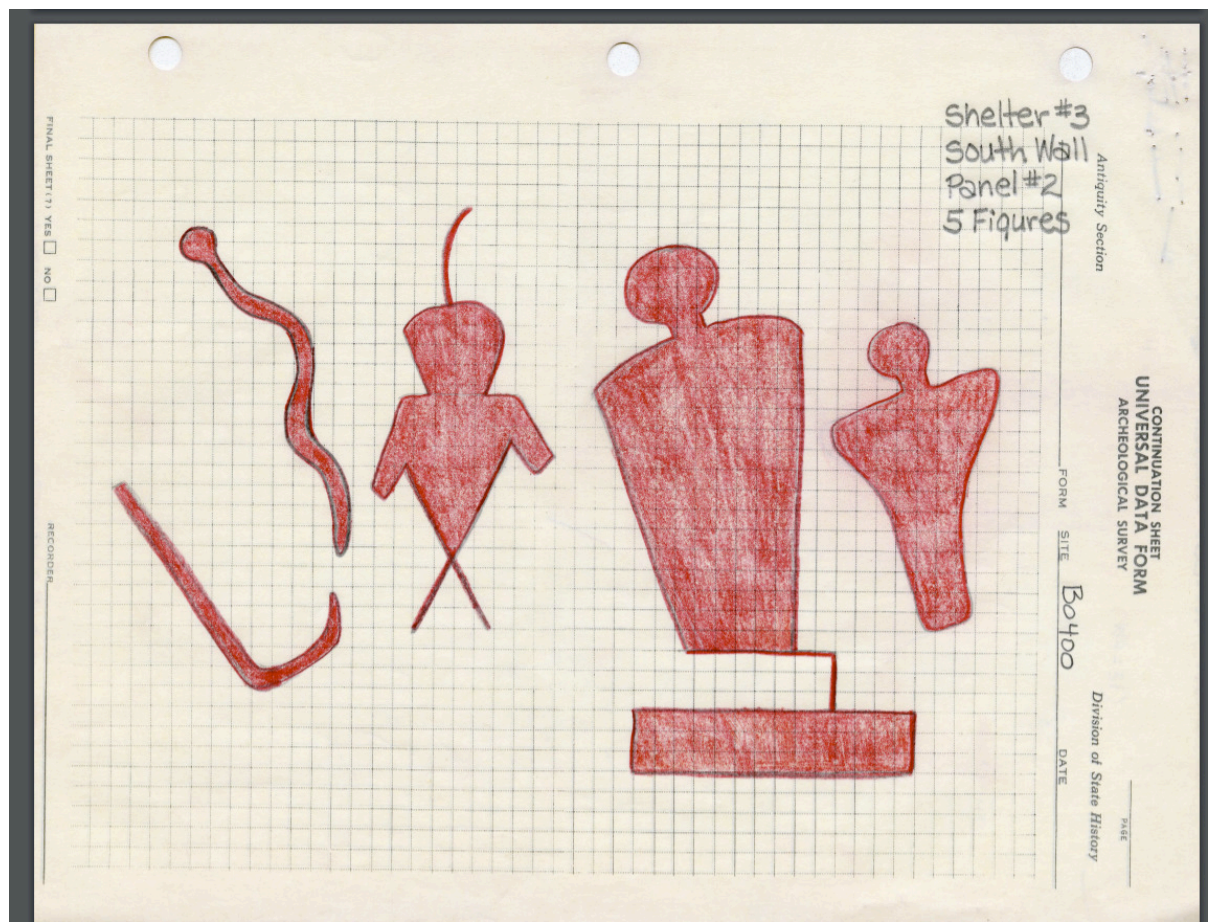

Figure 8

Source: Stuart, 1982

\section{H4: Anthropomorphs with Different Head Shapes}

Site 42BO582 shows anthropomorphs possibly holding hands with different head shapes and sizes. The hand holding could symbolize connectedness or an intersex relationship (Stuart, 1986). 


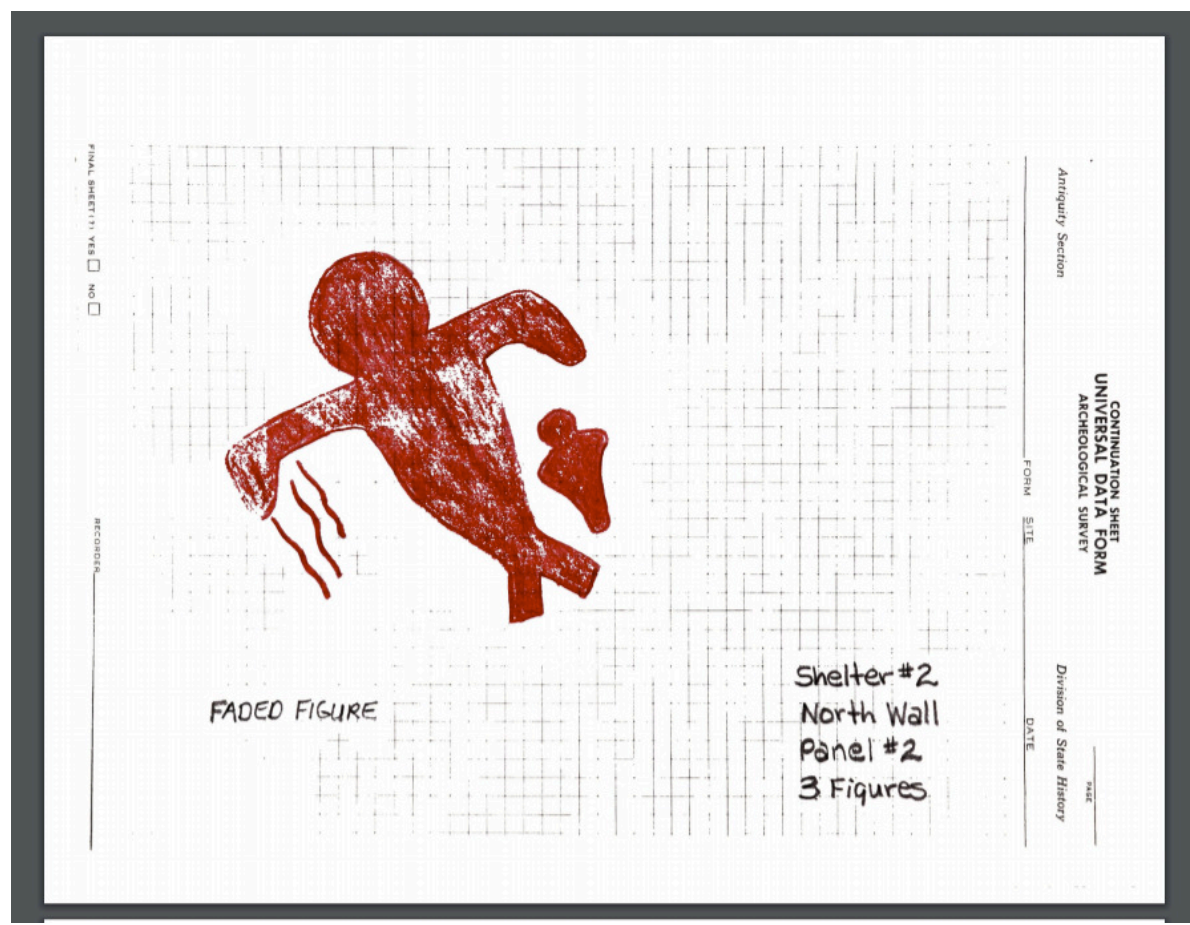

Figure 9: Adult and child.

Source: Stuart, 1982

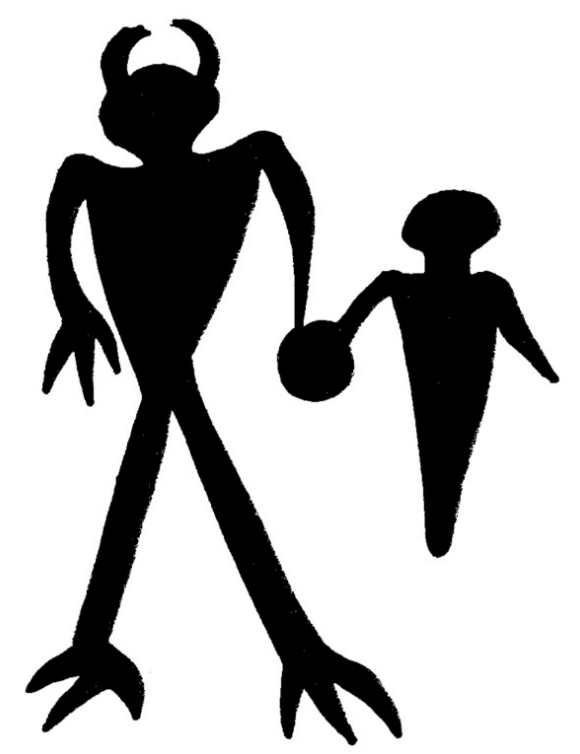

Figure 10: Big Man/Little Man Rock

Source: Stuart, 2007a

Site 42BO1703, nicknamed Table Rock, has anthropomorphs with interesting head shapes and one with a possible tail and demonic look (Stuart, 2007a). 


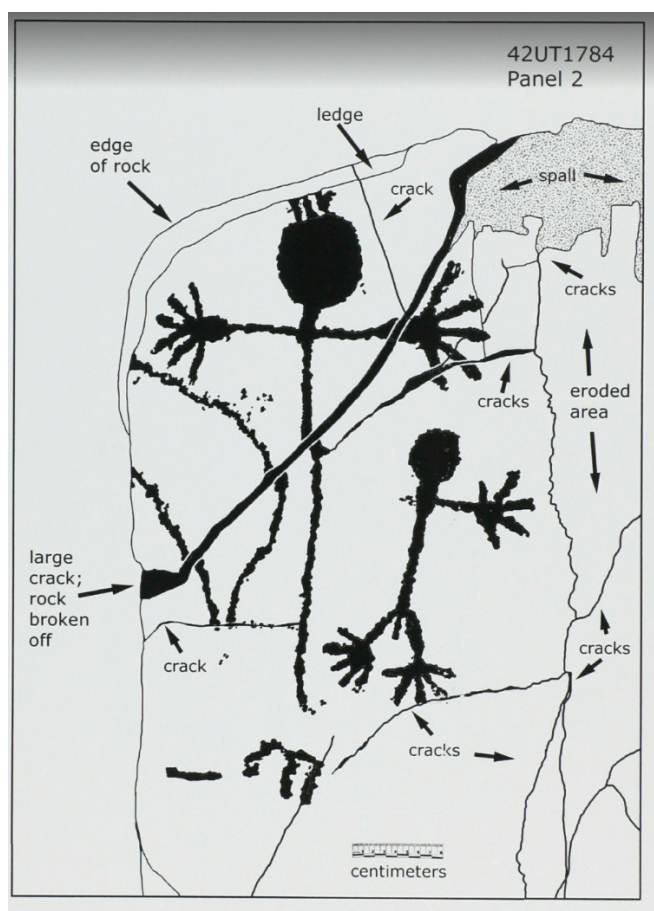

Figure 11: Two anthropomorphs of varying sizes, one with a line in between legs. Source: Manning, 2011

Figure 76: Close up view and sketch of more petroglyphs on west side of Burnt Rock

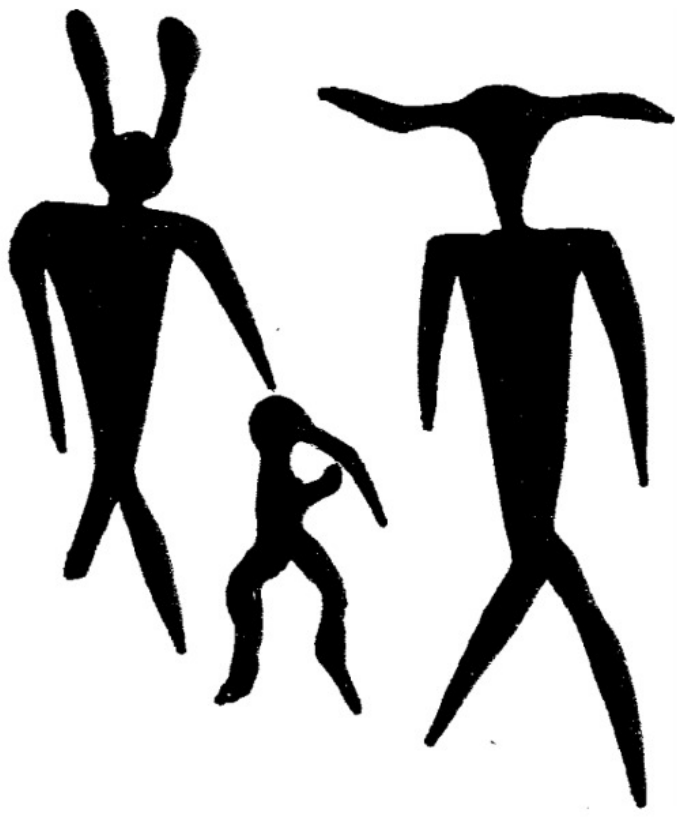

Figure 12: Family of Anthropomorphs.

Source: Stuart, 2007b

Site 42BO1707, nicknamed Frog Man Rock, includes a figure that is a therianthropomorph with a frog-like head and extremities on the main panel (Stuart, 2007b). 


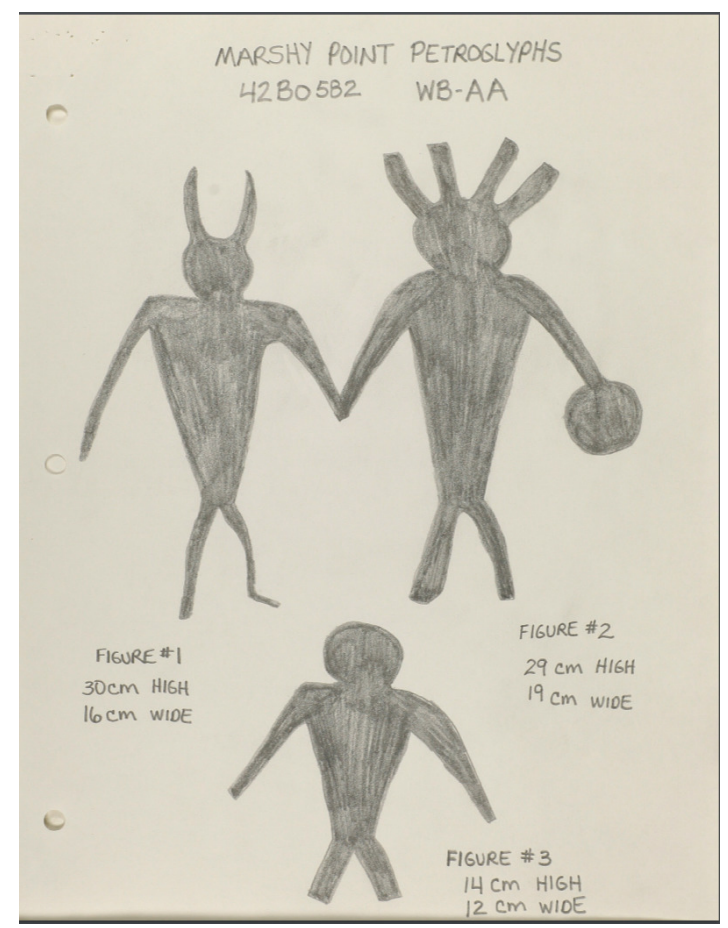

Figure 13: Anthropomorphs holding hands

Source: Stuart, 1986

Figure 67: Photo and sketch of Table Rock petroglyphs.

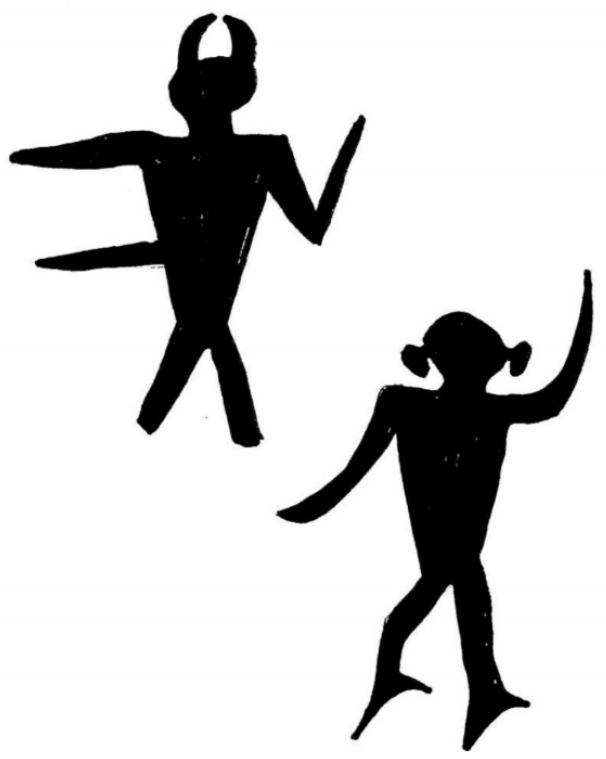

Figure 14: Two anthropomorphs with varying head shapes.

Source: Stuart, 2007a

Site 42TO160 has one panel with three differently shaped and sized anthropomorphs. Two of the figures have a line between the legs, possibly representing male genitalia. The head shapes of the anthropomorphs all vary as well (Cartwright, 1979b). 


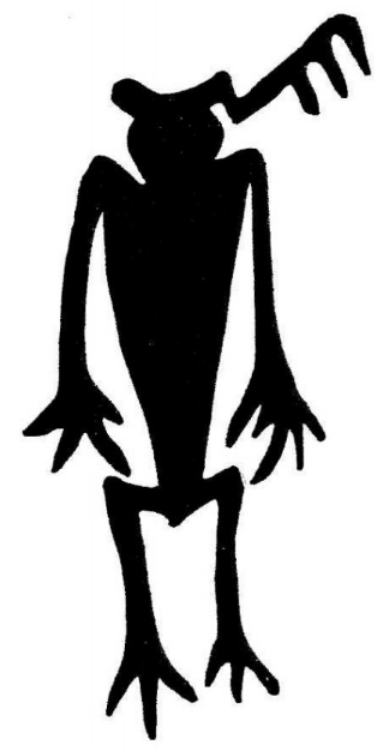

Figure 72: Sketch of Frogman petroglyph.

Figure 15: Frog Man Rock.

Source: Stuart, 2007b

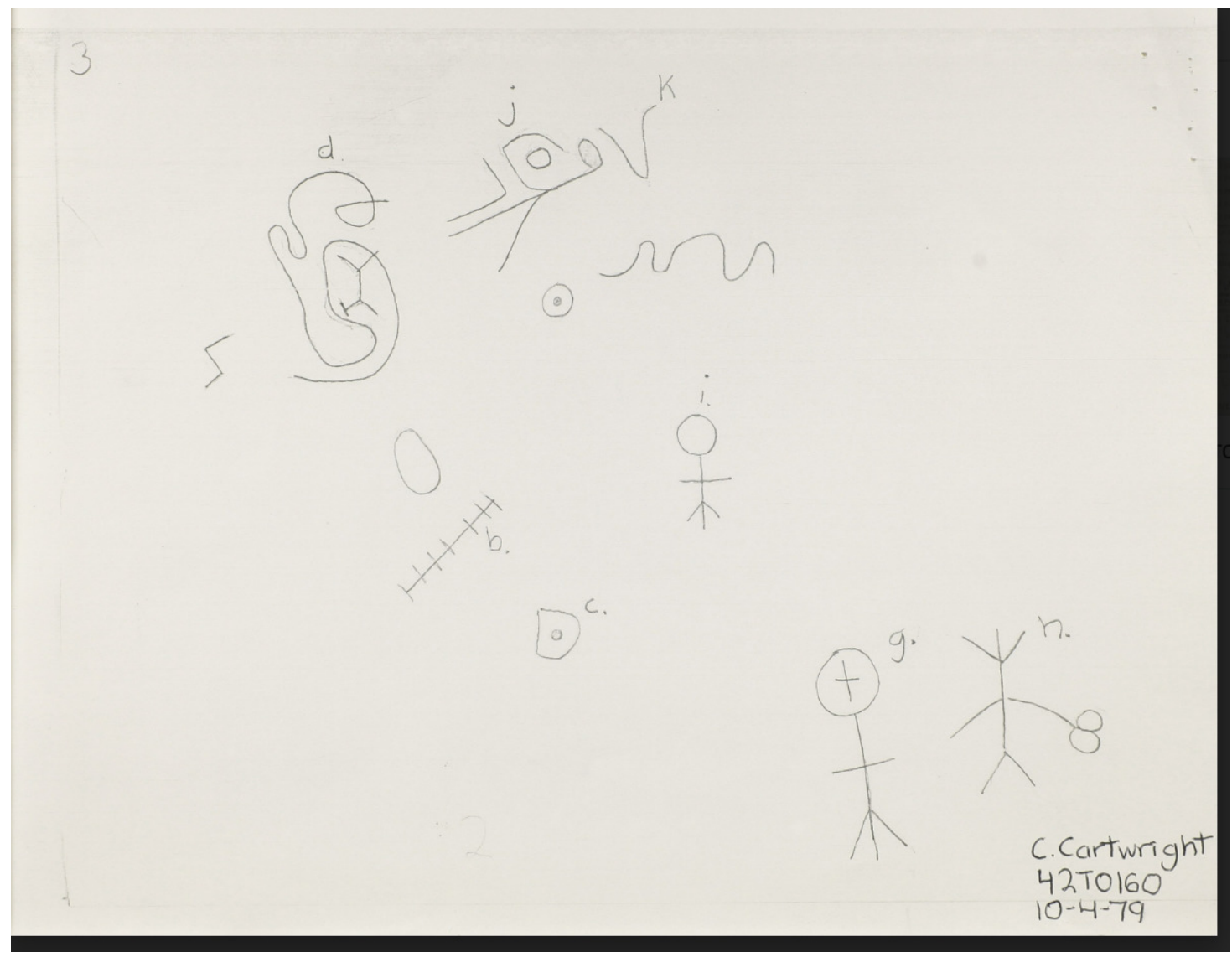

Figure 16: Various head shapes.

Source: Cartwright, 1979b 


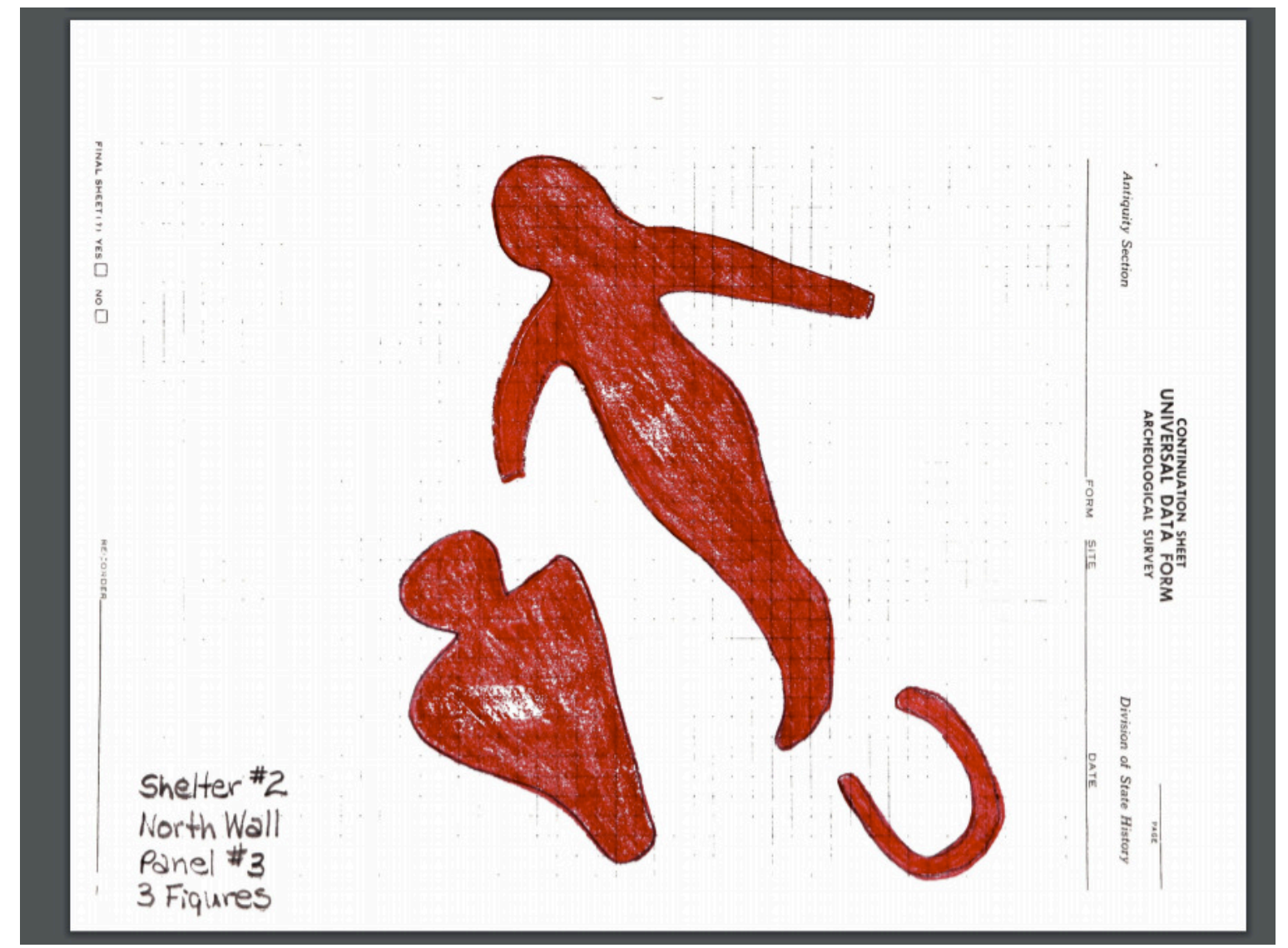

Figure 17: Cupule.

Source: Stuart, 1982

\section{H4: Concentric Circles and Cupules}

Site 42BO412 includes two anthropomorphs. One figure has a cupule below it, which is a trademark symbol of women's genitalia in rock art (HaysGilpin, 2004a; Stuart, 1982).

Site 42JB126 shows multiple anthropomorphs around concentric circles. The circles may represent women's fertility over time (Hays-Gilpin, 2004b; $\mathrm{KBO}, 1974)$.

Devil's Kitchen in Millard County includes many panels with concentric circles (Shipley, 2019).

Site 42TO209 shows one large anthropomorphic figure with concentric circles around it as well as a second figure. Both figures have horns (Cartwright, 1979a).

Site 42UT1746 includes a panel with multiple cupule peckings, which could represent a vulva or vagina (Hays-Gilpin, 2004a; Shipley, 2019).

\section{Analysis}

\section{Study Analysis}

Over 750 site forms were examined to look for any indication of gender or sex attributes. While there were a decent amount of anthropomorphs, there were also many therianthropes, anthropomorphs with animal heads, or extremities (Solomon, 1997). There were not many panels that displayed 


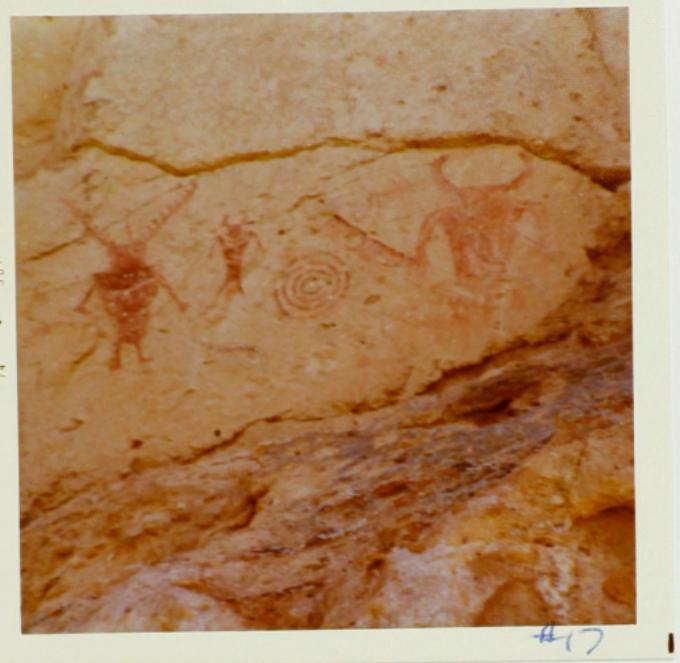

Figure 18: Concentric circles.

Source: KBO, 1974

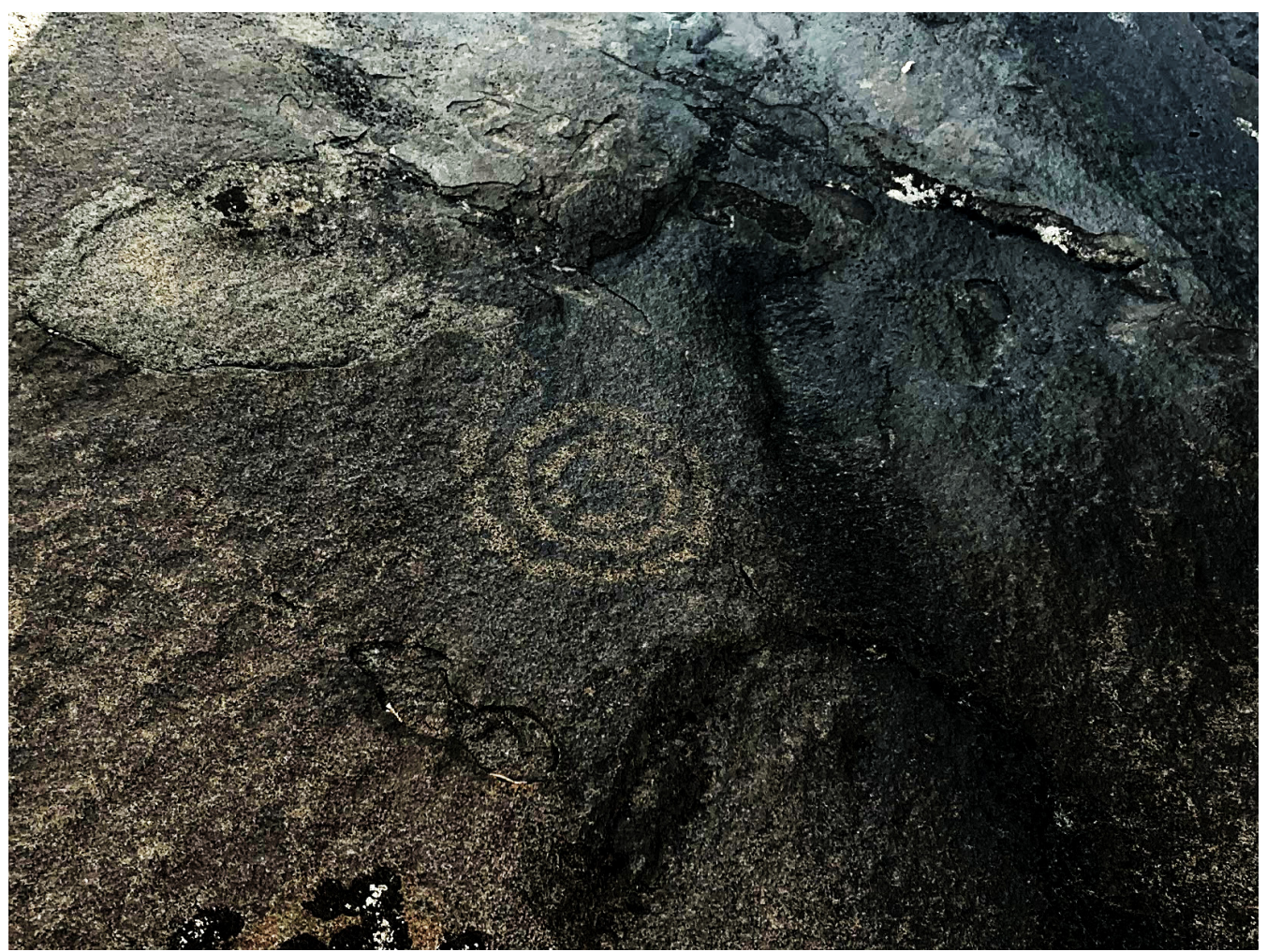

Figures 19

Source: Shipley, 2019

gender attributes. If the study included, for example, Moab in Grand County, there would have been more panels portraying gender roles. "The Birthing Rock" in Moab (Figure 25) is an example of rock art that clearly depicts women 


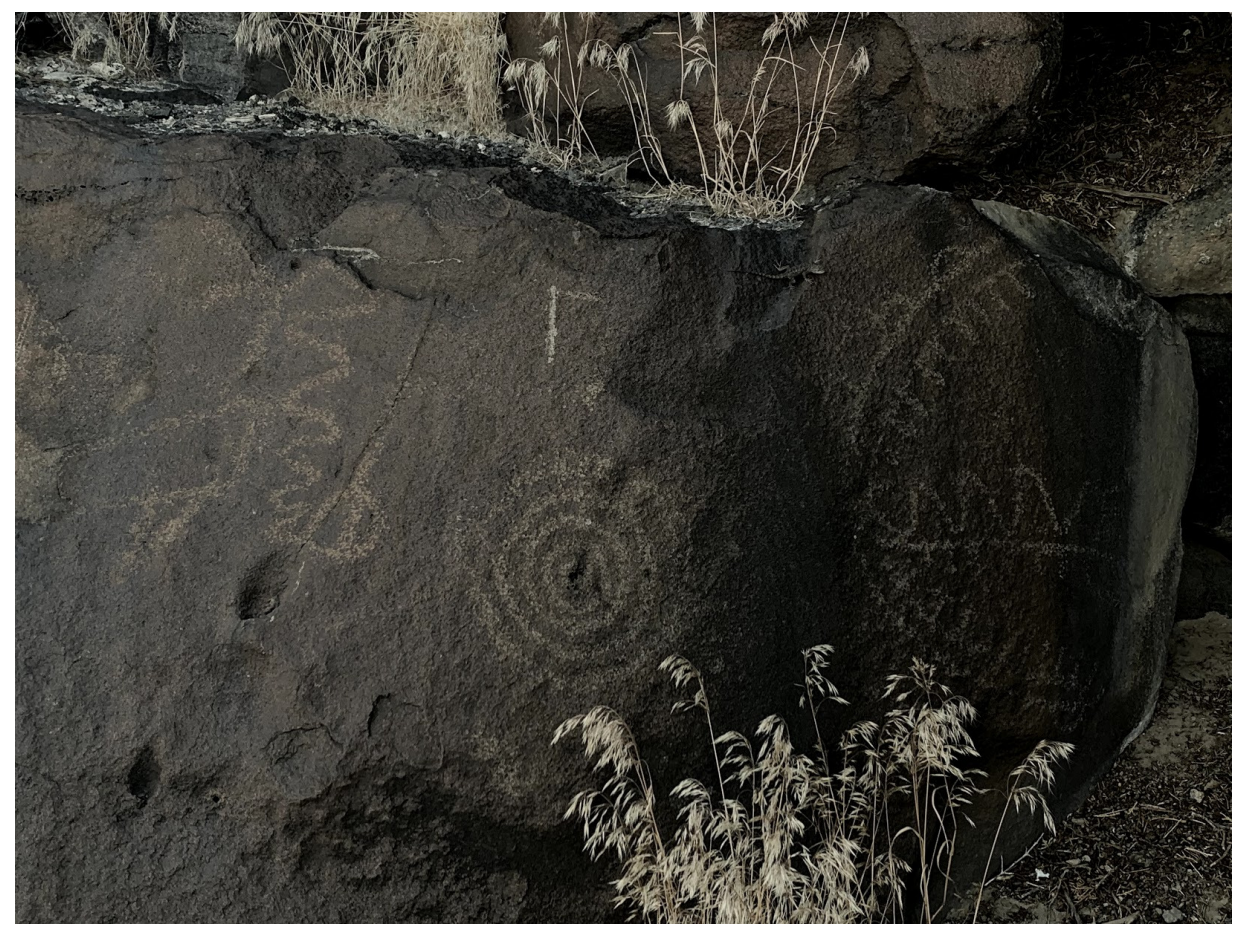

Figure 20

Source: Shipley, 2019

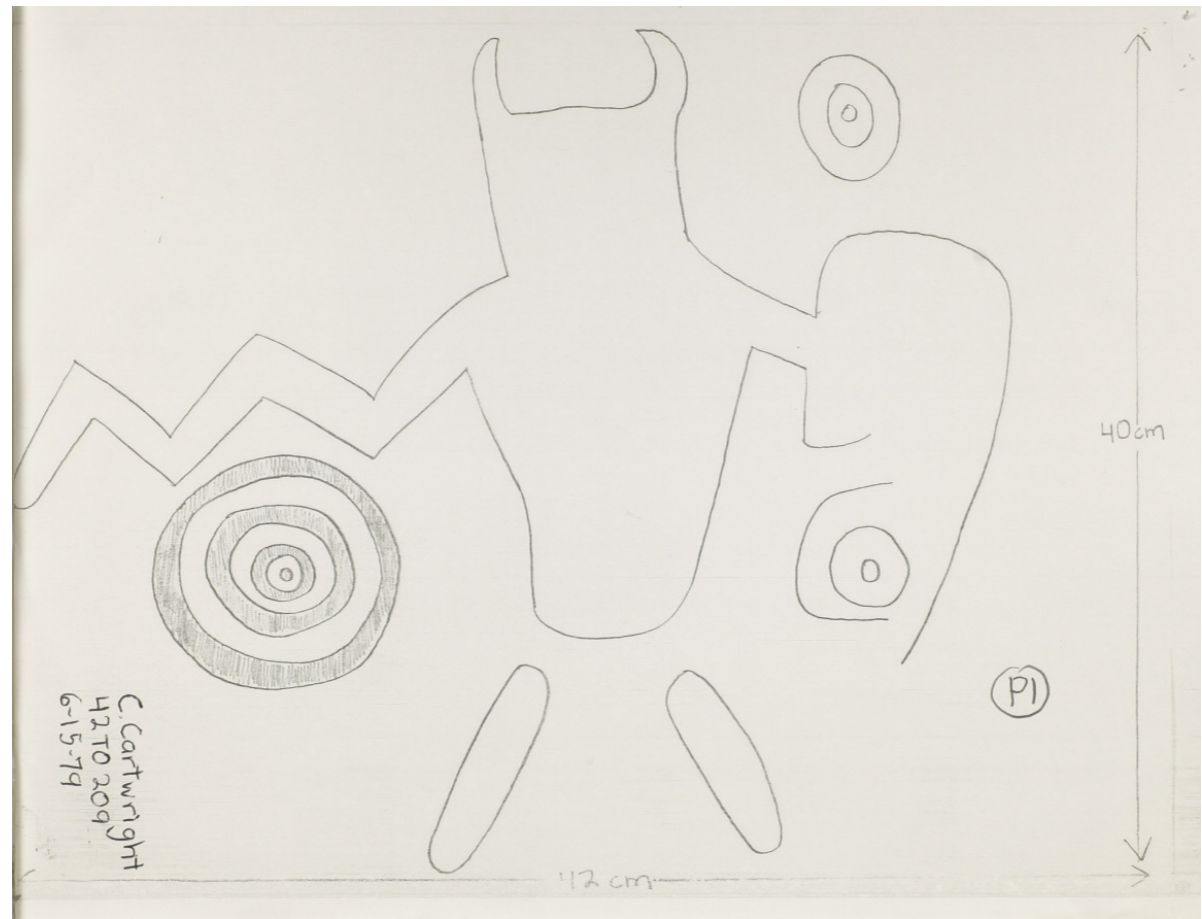

Figures 21

Source: Cartwright, 1979a

and women's roles ("Petroglyphs and Rock Art Sites - Discover Moab, Utah," 2017). Other popular rock art sites in Utah can be found on the URARA website. There are around 4200 documented rock art sites in Utah, so there likely are many more that represent gender/sex roles (Scotter \& Bowen, 2019). 


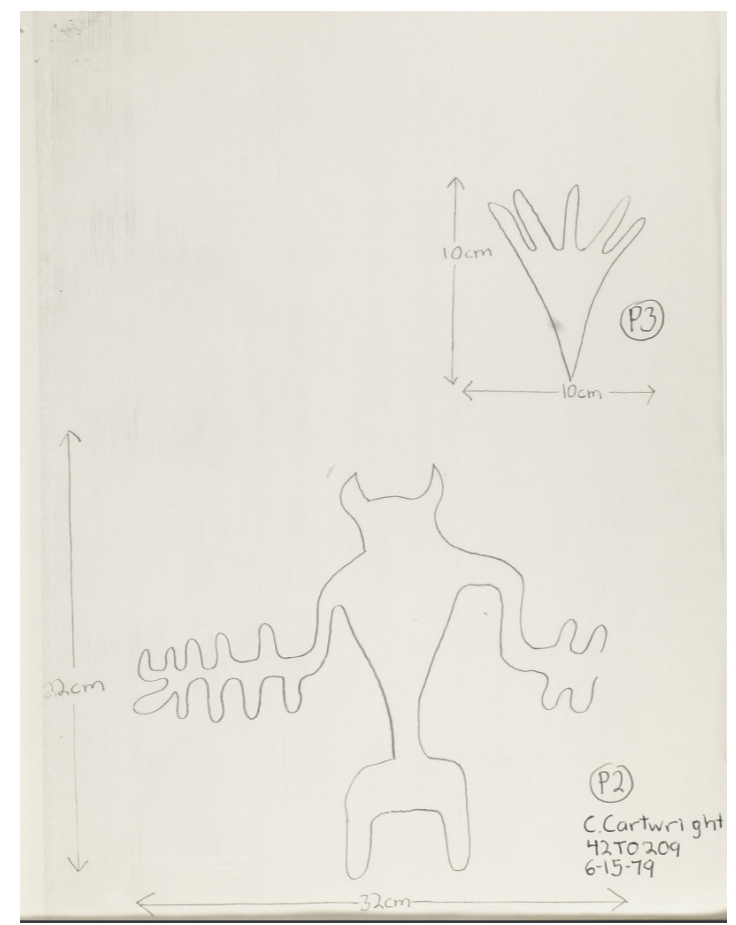

Figure 22

Source: Cartwright, 1979a

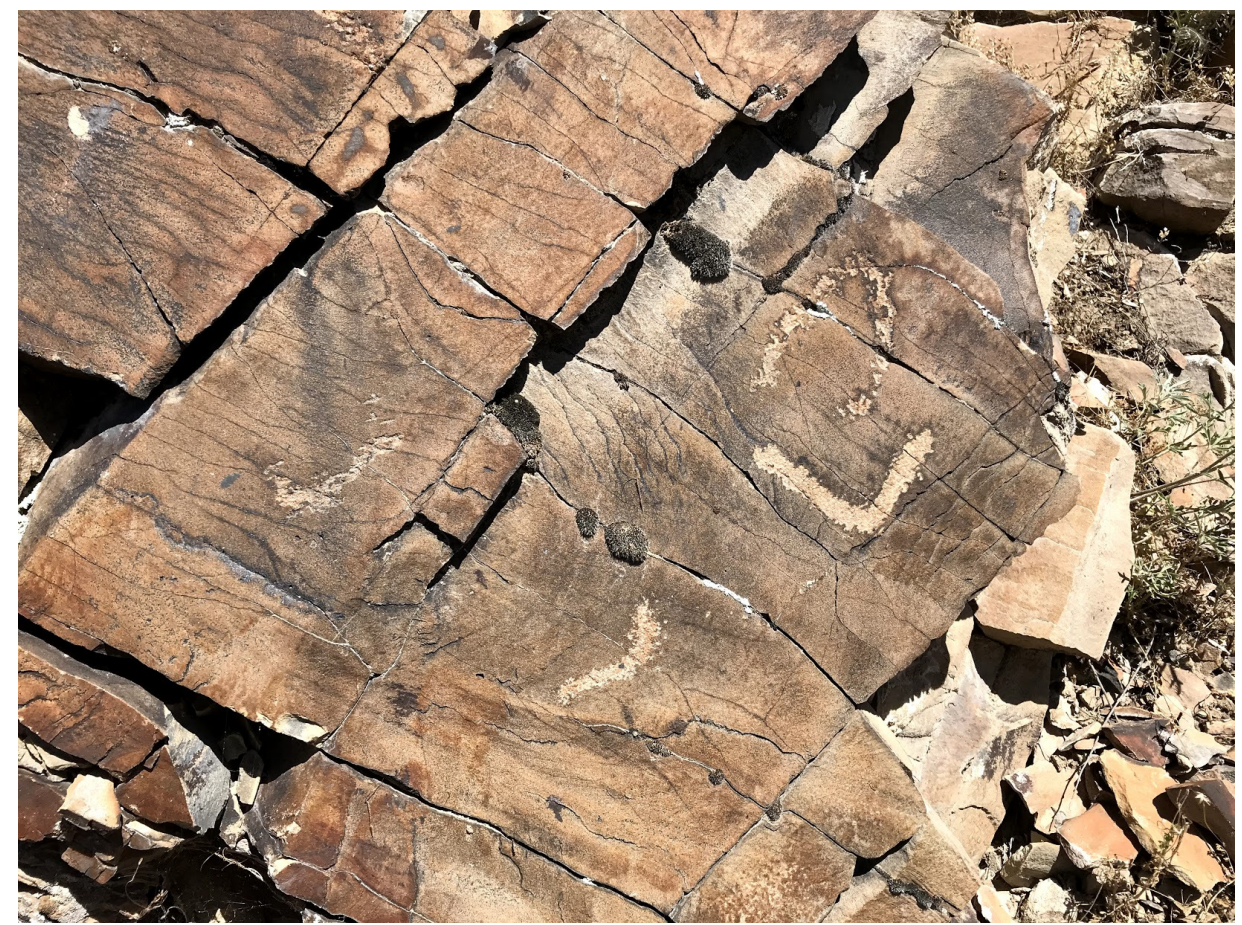

Figures 23

Source: Shipley, 2019

Gender attributions are difficult to come by among rock art in Utah, and just about everywhere else. Even though they are hard to find, gender and women's roles could have still been significant to the cultures which produced the art. Likewise, we cannot be sure that anthropomorphic figures did not 


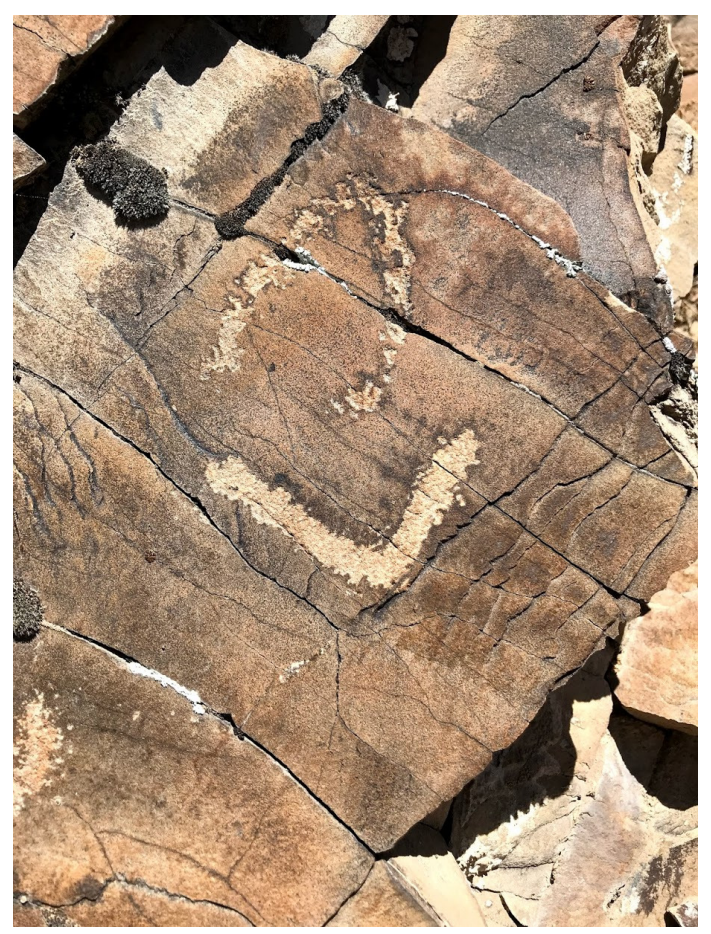

Figures 24

Source: Shipley, 2019

represent both males and females. Symbols such as a cupule (as shown in Utah county site 42UT1746) could represent vulvas or vaginas, but there is no way of being certain

As described by Kelley Hays-Gilpin, these images are "ambiguous" and cannot have an absolute interpretation unless given by the author themself (Hays-Gilpin, 2004a). It is hard to even make an educated guess without having a great understanding of the people who produced the art. However, we do know hunter-gatherer societies are responsible for most rock art production in western North America (Whitley, 1998). Further research in more counties, as well as cross-comparison with other sites outside of Utah, might be beneficial in learning more about sites in Utah.

Other than similarities in styles, there were not common patterns within or among counties. If the rock art does contain any anthropomorphic figures, most do not contain sex/gender attributes. We cannot make a positive determination without understanding the culture that created it.

\section{Conclusion and Contributions of the Study}

Though some rock art motifs can be more easily interpreted, most require extensive knowledge on the culture and ethnographic analysis to reach a probable conclusion. Identifying sex and gender within rock art motifs can be difficult without understanding the cultural construction as we oftentimes have biases and cultural assumptions of our own. Some research on gender/ sex characteristics in rock art are present, but there is more to be studied, particularly needed are ethnographic studies and more accurate dating methods with the art. 


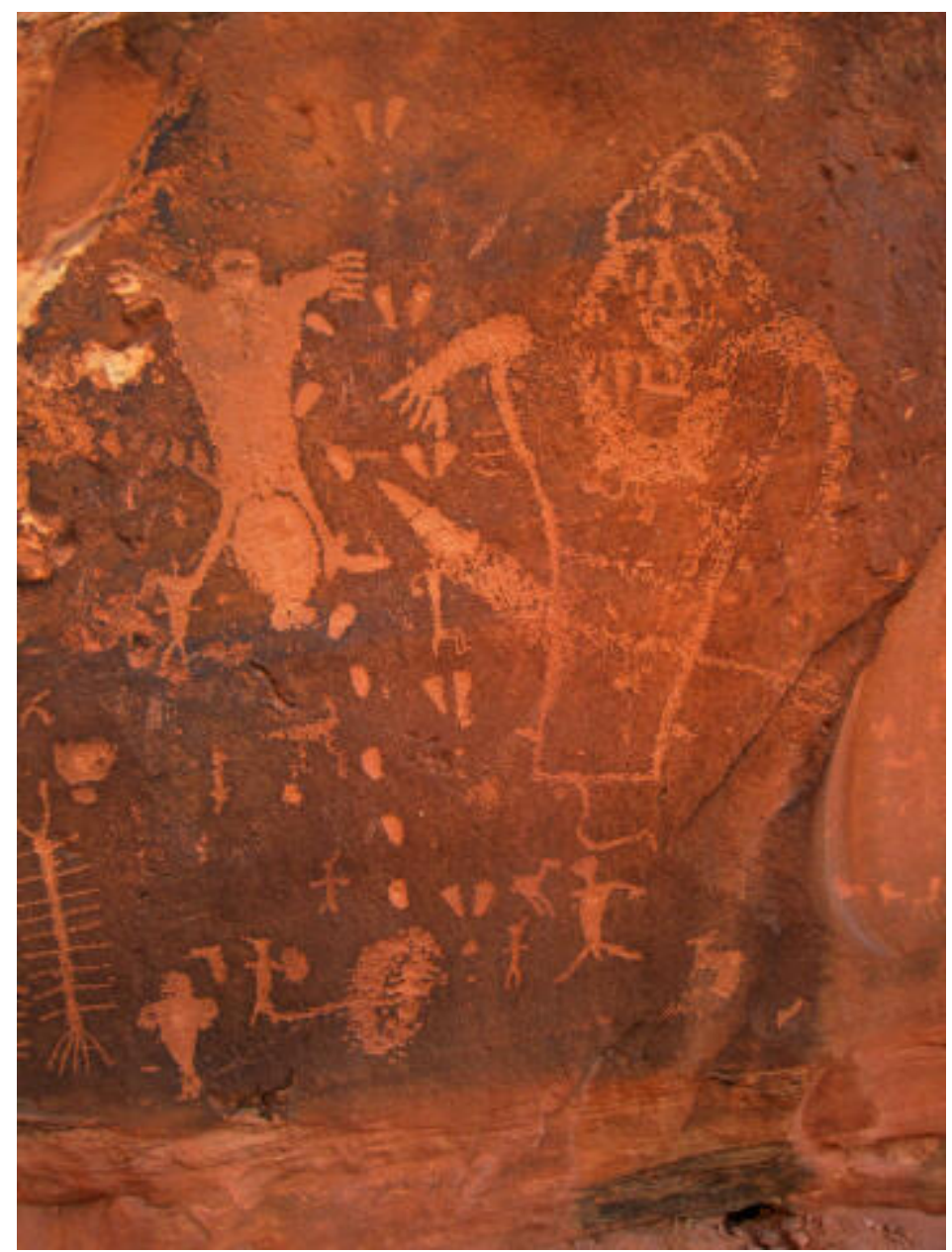

Figure 25

Source: Climb-Utah.com, 2000

The artwork of a culture cannot be disregarded or taken lightly; "Art has to be taken seriously, as a result of situated reflection and engagement within a particular environment" (Porr \& Bell, 2012). Rock art can tell us so much about a culture's cosmology and lifestyle. Understanding how gender is portrayed in rock art can give light as to how gender relations worked within a prehistoric society. What This Awl Means : Feminist Archaeology at a Wahpeton Dakota Village by Janet D. Spector (1993) and Ambiguous Images by Kelley Hays-Gilpin (2004a) are both instrumental in understanding how gender biases are rooted in archaeology and how we can study gender in rock art. This study can help in the "de-gendering" of archaeology and how we study rock art. However, we can never be certain that rock art portrays gender/sex characteristics. 


\section{References}

Bader, L. (2014). Third Genders: New Concept? Or Old?| The Evolution of Human Sexuality. Psu.Edu. https://sites.psu.edu/evolutionofhumansexuality/2014/02/19/third-genders-new-concept-or-old/

Barger, M. (1978). Antiquities Site Inventory: 42BO386. Utah Department of Heritage and Arts.

Bass, P. M. (1994). Chapter 6: A Gendered Search Through Some West Texas Rock Art. In D. S. Whitley \& L. L. Loendorf(Eds.), New Light on Old Art: Recent Advances in Hunter-Gatherer Rock Art Research (pp. 67-74). Cotsen Institute of Archaeology Press.

Bednarik, R. (2015). The First Stirrings of Creation. Academia. https://www.academia.edu/ 11300516/The_first_stirrings_of_creation

Bowen, N., \& Manning, S. J. (2003). Utah Rock Art. Papers Presented at the Twenty-First Annual Symposium of the Utah Rock Art Research Association (URARA).

Brady, L. M. (2016). Contemporary Indigenous Relationships to Archaeological Features: Agency, Affect, and the Social Significance of Rock Art. Heritage E' Society, 9(1), 3-24. https://doi.org/ $\underline{10.1080 / 2159032 \times .2016 .1246153}$

Cartwright, C. (1979a). Antiquities Site Inventory: 42TO160. Utah Department of Heritage and Arts.

Cartwright, C. (1979b). Antiquities Site Inventory: 42TO209. Utah Department of Heritage and Arts.

Climb-Utah.com. (2000). Birtbing Scene. https://www.climb-utah.com/Moab/birth.htm

Cole, S. J. (2009). Legacy on Stone: Rock Art of the Colorado Plateau and Four Corners Region. Johnson Books.

Frink, L., Shepard, R. S., \& Reinhardt, G. A. (Eds.). (2002). Many Faces of Gender: Roles and Relationships through Time in Indigenous Northern Communities. University Press of Colorado.

Garrison, L. T. (2017). 6 Modern Societies Where Women Rule. Mental Floss. http://mentalfloss.com/article/31274/6-modern-societies-where-women-literally-rule

Geib, P. R., \& Fairley, H. C. (1992). Radiocarbon Dating of Fremont Anthropomorphic Rock Art in Glen Canyon, South-Central Utah.Journal of Field Archaeology, 19(2), 155. https://doi.org/ $\underline{10.2307 / 529976}$

Gero, J. M., \& Conkey, M. W. (2002). Engendering Archaeology: Women and Prehistory. WileyBlackwell.

Handsman, R. G. (2002). Whose Art Was Found at Lepenski Vir? Gender Relations and Power in Archaeology. In Engendering Archaeology: Women and Prebistory (pp. 329-365). Wiley-Blackwell.

Hays-Gilpin, K. (2004a). Chapter 6: Gender and Prehistoric Rock Art. In S. M. Nelson (Ed.), Ambiguous Images: Gender and Rock Art (pp. 122-141). Altamira Press.

Hays-Gilpin, K. (2004b). Chapter 12: Engendering Rock Art. In S. M. Nelson (Ed.), Ambiguous Images: Gender and Rock Art (pp. 199-213). Altamira Press.

Healy, M. (1999). IMACS Site Form: 42UT1586. Utah Department of Heritage and Arts.

Hedges, R. E. M., Housley, R. A., Law, I. A., \& Perry, C. (1987). Radiocarbon Dates from the Oxford AMS System: Archaeometry Date List 6. Archaeometry, 29(1), 289-306. https://doi.org/10.1111/ j.1475-4754.1988.tb00443.x

KBO. (1974). Survey Site Sheet: 42JB126. Utah Department of Heritage and Arts.

Keyser, J. D. (2001). Relative Dating Methods. In D. S. Whitley (Ed.), Handbook of Rock Art Research (pp. 116-138). Altamira Press.

Liritzis, I. (2010). Strofilas (Andros Island, Greece): New Evidence for the Cycladic Final Neolithic Period through Novel Dating Methods Using Luminescence and Obsidian Hydration. Journal of Archaeological Science, 37(6), 1367-1377. https://doi.org/10.1016/j.jas.2009.12.041 
Lødøen, T. (2003). Late Mesolithic Rock Art and Expressions of Ideology. In H. Kingdom, K. Knuttson, L. Larsson, \& D. Leoffler (Eds.), Mesolithic on the Move: Papers Presented at the Sixth International Conference on the Mesolithic in Europe, Stockholm 2000. Oxbow.

Manning, S. J. (2011). IMACS Site Form: 42UT1784. Utah Department of Heritage and Arts.

McMurtrey, K. (2015). Patterns in Rock Art: An Analysis of the Fremont Rock Art at the Smith Preserve.

Miller, B. (1996). IMACS Site Form: 42CB1045. Utah Department of Heritage and Arts.

Mullen, L. (2011). Reverence for the Heavens: How Astronomy and Religion Intersect. Space.Com. https://www.space.com/10656-astronomy-religion-cosmos-intersection.html

Namono, C. (2012). Dumbbells and Circles: Symbolism of Pygmy Rock Art of Uganda. Journal of Social Archaeology, 12(3), 404-425. https://doi.org/10.1177/1469605312455761

Namono, C., \& Eastwood, E. B. (2005). Art, Authorship and Female Issues in a Northern Sotho Rock Painting Site. Goodwin Series, 9(1), 77-85. https://doi.org/10.2307/3858036

Neculaesei, A. (2015). Culture and Gender Role Differences. Cross Cultural Management Journal, 1(1), 31-35. https://econpapers.repec.org/RePEc:cmj:journl:y:2015:i:7:p:31-35

Petroglyphs and Rock Art Sites - Discover Moab, Utah. (2017). Discover Moab. https://www.discovermoab.com/rock-art-sites/

Porr, M., \& Bell, H. R. (2012). 'Rock-art', 'Animism' and Two-way Thinking: Towards a Complementary Epistemology in the Understanding of Material Culture and 'Rock-art' of Hunting and Gathering People. Journal of Archaeological Method and Theory, 19(1), 161-205. https://doi.org/10.1007/s10816-011-9105-4

Rogers, R. A. (2007). From Hunting Magic to Shamanism: Interpretations of Native American Rock Art and the Contemporary Crisis in Masculinity. Women's Studies in Communication, 30(1), 78-110. https://doi.org/10.1080/07491409.2007.10162506

Rosenfeld, A., \& Smith, M. (2002). Rock-Art and the History of Puritjarra Rock Shelter, Cleland Hills, Central Australia. Proceedings of the Prehistoric Society, 68(1), 103-124. https://doi.org/ $10.1017 / \mathrm{s} 0079497 \times 00001407$

Rowe, M. W. (2001). Dating by AMS Radiocarbon Analysis. In D. S. Whitley (Ed.), Handbook of Rock Art Research (pp. 139-166). Altamira Press.

Sabo, G., \& Sabo, D. (2019). What Is Rock Art and What Can It Tell Us about the Past? Uark.Edu. http://archeology.uark.edu/rockart/ index.html?pageName=What\%20is\%20Rock\%20Art\%20and\%20What\%20Can\%20it\%20Tell\%20Us\%20About\%20the

Sauvet, G. (2015). In Search of Lost Time. Dating Methods for Prehistoric Art: The Example of Aurignacian Sites. Palethnologie, 1(7). https://doi.org/10.4000/palethnologie.823

Schaafsma, P. (1971). The Rock Art of Utah: A Study from the Donald Scott Collection. University of Utah Press.

Scotter, T., \& Bowen, N. (2019). The Rock Art of Utah. Utab Rock Art Research Association (URARA). https://urara.wildapricot.org/page-18203

Shipley, S. C. (2019). Site Form: 42UT1746. Utah Department of Heritage and Arts.

Solomon, A. (1997). The Myth of Ritual Origins? Ethnography, Mythology and Interpretation of San Rock Art. The South African Archaeological Bulletin, 52(165), 3-13. https://doi.org/10.2307/ $\underline{3888971}$

Spangler, J. (2007). IMACS Site Form: 42CB958. Utah Department of Heritage and Arts.

Spector, J. D. (1993). What This Awl Means: Feminist Archaeology at a Wahpeton Dakota Village.

Minnesota Historical Society Press.

Stuart, M. E. (1982). Site Survey Sheet: 42BO400. Utah Department of Heritage and Arts. 
Stuart, M. E. (1985). IMACS Site Form: 42BO2114. Utah Department of Heritage and Arts.

Stuart, M. E. (1986). IMACS Site Form: 42BO582. Utah Department of Heritage and Arts.

Stuart, M. E. (2007a). IMACS Site Form: 42BO1703. Utah Department of Heritage and Arts.

Stuart, M. E. (2007b). IMACS Site Form: 42BO1707. Utah Department of Heritage and Arts.

Whitley, D. S. (1998). Finding Rain in the Desert: Landscape, Gender and Far Western North American Rock-Art. In The Archaeology of Rock-Art (pp. 11-27). Cambridge University Press.

WorldAtlas, \& Sawe, B. E. (2019). Matriarchal Societies around the World. WorldAtlas. https://www.worldatlas.com/articles/matriarchal-societies-around-the-world.html

Wright, A. M., \& Russell, W. G. (2011). The Pipette, the Tiered Cosmos, and the Materialization of Transcendence in the Rock Art of the North American Southwest. Journal of Social Archaeology, 11(3), 361-386. https://doi.org/10.1177/1469605311403864

Wylie, A. (2002). Gender Theory and the Archaeological Record. In Why Is There No Gender of Archaeology? Engendering Archaeology: Women and Prehistory (pp. 31-56). Blackwell. 